\title{
Preparation and in vivo evaluation of an orally available enteric-microencapsulated parathyroid hormone (I-34)-deoxycholic acid nanocomplex
}

This article was published in the following Dove Press journal:

International Journal of Nanomedicine

3I August 2016

Number of times this article has been viewed

\author{
Seung Rim Hwang' \\ Dong-Hyun Seo ${ }^{2}$ \\ Youngro Byun ${ }^{3}$ \\ Jin Woo Park ${ }^{4}$
}

'Department of Pharmacy, College of Pharmacy, Chosun University,

Gwangju, ${ }^{2}$ Department of Biomedical

Engineering, College of Health

Science, Yonsei University, Wonju,

Gangwon, ${ }^{3}$ Department of Molecular

Medicine and Biopharmaceutical

Science, Graduate School of

Convergence Science and Technology,

College of Pharmacy, Seoul National

University, Seoul, ${ }^{4}$ Department of

Pharmacy, College of Pharmacy and

Natural Medicine Research Institute,

Mokpo National University, Muan-gun, Jeonnam, Republic of Korea
Correspondence: Youngro Byun College of Pharmacy, Seoul National University, I Gwanak-ro, Gwanak-gu, Seoul I5I-742, Republic of Korea

Tel +8228807866

Fax +8228727864

Email yrbyun@snu.ac.kr

Jin Woo Park

College of Pharmacy, Mokpo National

University, 1666 Youngsan-ro, Muan-gun, Jeonnam 58554, Republic of Korea

Tel +82 6I 4502704

Fax +82 6I 4502689

Email jwpark@mokpo.ac.kr
Abstract: The $N$-terminal 34-amino-acid peptide fragment of human parathyroid hormone PTH (1-34), is used clinically to treat osteoporosis; however, it is currently administered by a once-daily subcutaneous injection, resulting in poor patient compliance. We have developed enteric microcapsules containing an ionic nanocomplex between PTH (1-34) and lysine-linked deoxycholic acid (LysDOCA) for the oral delivery of PTH (1-34). We measured the particle size of the PTH/LysDOCA complex and assessed its biological activity by determining the cAMP content in MC3T3-E1 cells. We also assessed its permeability across a Caco-2 cell monolayer and the bioavailability of the intrajejunally administered PTH/LysDOCA complex compared with PTH (1-34) in rats. In addition, the antiosteoporotic activity of the PTH/LysDOCA complex, encapsulated in an enteric carrier by coaxial ultrasonic atomization, was evaluated after it was orally administered to ovariectomized (OVX) rats. The formation of an ionic complex between PTH (1-34) and LysDOCA produced nanoparticles of diameter 33.0 $33.36 \mathrm{~nm}$, and the bioactivity of the complex was comparable with that of PTH (1-34). The Caco-2 cell permeability and $\mathrm{AUC}_{\text {last }}$ value of the PTH/LysDOCA (1:10) nanocomplex increased by 2.87- and 16.3-fold, respectively, compared with PTH (1-34) alone. Furthermore, the OVX rats treated with oral PTH/LysDOCA-loaded enteric microcapsules showed an increase in bone mineral density (159\%), bone volume fraction (175\%), and trabecular number (174\%) compared with those in the OVX control group. Therefore, the PTH/LysDOCA nanocomplex oral delivery system is a promising treatment modality for osteoporosis because it improves osteogenesis and trabecular connectivity.

Keywords: oral delivery, parathyroid hormone, nanocomplex, deoxycholic acid, coaxial ultrasonic atomization, osteoporosis

\section{Introduction}

Parathyroid hormone (PTH), a polypeptide consisting of 84 amino acids secreted from the parathyroid glands, is one of the major hormones regulating the calcium ion concentration in the blood. ${ }^{1}$ It has anabolic (ie, bone-building) and catabolic functions in bone, and these depend on the pattern and duration of PTH exposure. ${ }^{2}$ Anabolic functions are stimulated by intermittent exposure to $\mathrm{PTH}$, resulting in differentiation and proliferation or reduced apoptosis of osteoblasts. ${ }^{3-5}$ Catabolic functions are stimulated by continuous PTH exposure and associated with increased receptor activator of nuclear factor- $\mathrm{\kappa B}$ ligand expression and inhibition of osteoprotegerin expression. ${ }^{6}$

The $34 N$-terminal amino acids of PTH, PTH (1-34), are indispensable for activating the type 1 PTH receptor, which is highly expressed in bone and kidney. ${ }^{7}$ When PTH (1-34) binds the type 1 PTH receptor, signaling pathways, which include the 
G protein-dependent cAMP/protein kinase A (PKA) pathway, are activated and the serum calcium level is regulated. Teriparatide, a recombinant human PTH (1-34) (rhPTH [1-34]), is used clinically to treat osteoporosis in postmenopausal women and hypogonadal osteoporosis in men. Intermittent teriparatide administration stimulates new bone formation by activating osteoblasts more than osteoclasts and reduces the risk of bone fractures in osteoporosis. ${ }^{8-10}$ Many other osteoporosis treatments have no anabolic properties and function solely as preventive therapies by suppressing osteoclast activity. These antiresorptives include bisphosphonates, estrogen receptor modulators, and calcitonin. ${ }^{11-13}$ Teriparatide can be used to treat osteoporosis in patients at risk of fractures who have failed to respond to antiresorptives.

Teriparatide is currently administered by a once-daily subcutaneous injection in the thigh or abdomen for a period of up to 2 years. To improve patient compliance, alternative delivery systems for the PTH (1-34) peptide have been attempted, including oral, transdermal, and nasal routes. ${ }^{14-16}$ Advantages of oral administration include convenience for the patient and an increase in the time required to reach the maximum plasma concentration $\left(T_{\max }\right)$ for PTH (1-34). ${ }^{14}$ However, one of the major challenges with the oral delivery of PTH (1-34) is that the oral bioavailability of the peptide itself may be poor. The reasons for this include the short half-life of the peptide, its degradation by gastric acid and gastrointestinal (GI) proteolytic enzymes, and its low membrane permeability due to its high molecular weight (which for PTH [1-34] is 4,117.72 Da). ${ }^{17,18}$

Approaches that use delivery agents or delivery vehicles have also been investigated for PTH (1-34). Oral administration of rhPTH (1-34) with 8-( $N$-2-hydroxy-4-methoxybenzoyl) amino caprylic acid as a delivery agent restored bone mass in a rat model of osteoporosis to a level comparable to that with subcutaneous injection of rhPTH (1-34). ${ }^{19}$ Meanwhile, chitosan nanoparticles prepared by ionic gelation were evaluated in vitro as PTH (1-34) delivery vehicles. ${ }^{20}$ To overcome the drawback that the amine groups were left exposed to chitosan nanoparticles, resulting in hemolysis, the surface of the particles was modified using polyethylene glycol, thus maintaining a steady PTH (1-34) serum concentration. ${ }^{21}$

Bile acid derivatives have also shown the potential for enhancing amphiphilicity and oral absorption of drugs. Previously, we found that lysine-linked deoxycholic acid (LysDOCA), an enhancer derived from bile acid, increased the intestinal absorption and oral bioavailability of ionically complexed drugs such as insulin and zoledronic acid. ${ }^{22}$ The aim of the present study was to develop an oral delivery system based on enteric microcapsules containing a nanocomplex of PTH (1-34) with LysDOCA. We hypothesized that enteric-microencapsulated rhPTH (1-34)/LysDOCA nanocomplexes will exhibit enhanced oral absorption properties and equivalent therapeutic efficacies in comparison with teriparatide administered by injection. The physicochemical characteristics, in vitro bioactivity, permeability through a Caco-2 cell monolayer, oral bioavailability, and in vivo antiosteoporotic efficacy of rhPTH (1-34)/ LysDOCA complexes were all assessed.

\section{Materials and methods Materials}

Recombinant human PTH (1-34) (teriparatide, rhPTH [1-34]) was prepared by GL Biochem (Shanghai, People's Republic of China). $N$-Methylmorpholine, deoxycholic acid (DOCA), ethyl chloroformate, $N^{\varepsilon}$-Boc-L-lysine methyl ester hydrochloride (H-Lys(Boc)-OMe-HCl), and 2,2,2-trifluoroethanol (TFE) were from Sigma-Aldrich Co. (St Louis, MO, USA). Poly(methacylic acid-co-ethyl acrylate) (Eudragit L100-55) was obtained as a sample from Evonik Nutrition \& Care GmbH (Essen, Germany). Tetrahydrofuran, chloroform, acetyl chloride, methanol, and $n$-hexane (analytical grade) were purchased from EMD Millipore/Merck (Billerica, MA, USA). High-performance liquid chromatography (HPLC)grade solvents were obtained from Thermo Fisher Scientific (Waltham, MA, USA) and EMD Millipore.

\section{Formation of rhPTH (I-34)/LysDOCA nanocomplex}

LysDOCA was synthesized under optimal reaction conditions as follows: $N$-methylmorpholine (7.4 mL, $67.24 \mathrm{mmoL})$ was added to DOCA (24 g, $61.13 \mathrm{mmoL})$ dissolved in dry tetrahydrofuran $(300 \mathrm{~mL})$, followed by ethyl chloroformate (6.4 mL dropwise), all in an ice bath. ${ }^{22,23}$ After stirring for 30 minutes, the reaction mixture was incubated at room temperature for 2 hours. H-Lys(Boc)-OMe $\mathrm{HCl}(20 \mathrm{~g}$, $67.24 \mathrm{mmoL}$ ) was added to the reaction filtrate, followed by reflux for 5 hours. After cooling to room temperature, the solvent was evaporated. $\mathrm{NaOH}(20 \mathrm{~mL})$ was added to the concentrate to a total of $15 \%$, and then extracted with chloroform. After drying with $\mathrm{Na}_{2} \mathrm{SO}_{4}$ and evaporation, $\mathrm{Lys}$ (Boc) DOCA was obtained. This was stirred in a mixture of acetyl chloride (23.4 mL, $329 \mathrm{mmoL})$ and methanol (100 mL) under nitrogen overnight. After solvent evaporation, the residue dissolved in distilled water was washed with chloroform. LysDOCA was obtained as a white powder by lyophilization of the aqueous layer. 
The rhPTH (1-34)/LysDOCA complex (PTH/LysDOCA) was formed by ionic interaction between rhPTH (1-34) and LysDOCA. rhPTH (1-34) and LysDOCA were separately dissolved in distilled water at a concentration of $1 \mathrm{mg} \mathrm{mL}^{-1}$, and the LysDOCA solution was added to the rhPTH (1-34) solution with vortexing. The feed molar ratio of rhPTH (1-34) to LysDOCA was 1:10. After the solution was centrifuged, the precipitate was immediately lyophilized to obtain PTH/ LysDOCA complex.

\section{Characterization of PTH/LysDOCA nanocomplex}

To characterize the secondary structure of the PTH/LysDOCA complex, the circular dichroism (CD) spectra of the rhPTH (1-34) or PTH/LysDOCA complex were obtained at $20^{\circ} \mathrm{C}$ with $10 \mu \mathrm{M}$ of $\mathrm{rhPTH}$ (1-34) or PTH/LysDOCA in water or $20 \%(\mathrm{v} / \mathrm{v})$ TFE. Measurements were made over the range 180-260 nm on a JASCO spectropolarimeter (Jasco Inc., Easton, MD, USA) using a $10 \mathrm{~mm}$ cuvette. All spectra were background-corrected and calculated in units of mean residual ellipticity. These represented an average of ten scans.

After complex formation, the particle size, size distribution, and surface charge were also measured using a dynamic light-scattering analyzer (Nano ZS; Malvern Instruments, Malvern, UK). The morphological evaluation of negatively stained nanocomplexes was performed by transmission electron microscopy (TEM; JEM-200; JEOL, Tokyo, Japan).

\section{In vitro bioactivity of PTH/LysDOCA complex}

Preosteoblast cells (MC3T3-E1 subclone 4; American Type Culture Collection [ATCC], Manassas, VA, USA) were cultured in $\alpha$-MEM with $10 \%$ fetal bovine serum in an atmosphere of $5 \% \mathrm{CO}_{2}$ at $37^{\circ} \mathrm{C}$. Cells were seeded at a density of $1 \times 10^{4}$ cells per well of a 96-well plate and incubated for 24 hours at $37^{\circ} \mathrm{C}$. After the growth medium was removed by suction, the cells were washed with $200 \mu \mathrm{L}$ of phosphatebuffered saline containing $0.5 \mathrm{mM}$ isobutylmethylxanthine. Then, $100 \mu \mathrm{L}$ of rhPTH (1-34) or PTH/LysDOCA complex solution in phosphate-buffered saline containing $0.5 \mathrm{mM}$ isobutylmethylxanthine (at concentrations of $0.01 \mu \mathrm{M}$, $0.1 \mu \mathrm{M}, 1.0 \mu \mathrm{M}, 10 \mu \mathrm{M}$, and $100 \mu \mathrm{M}$ ) was added to each well. After incubation for 1 hour at $37^{\circ} \mathrm{C}$, the cells were lysed by adding $100 \mu \mathrm{L}$ of $0.1 \mathrm{M} \mathrm{HCl}$ per well and incubating for another 10 minutes. Following centrifugation at $600 \times g$ for 10 minutes at room temperature, the amount of cAMP in each supernatant was quantified using a cAMP competitive enzyme-linked immunosorbent assay (ELISA) kit
(Thermo Fisher Scientific) according to the manufacturer's instructions.

\section{Caco-2 cell permeability study}

The permeability of rhPTH (1-34) or PTH/LysDOCA complex across a Caco-2 cell monolayer was evaluated as follows: Caco-2 cells were seeded onto Transwell ${ }^{\circledR}$ filter inserts (pore size, $0.4 \mu \mathrm{m}$; surface area, $1.12 \mathrm{~cm}^{2}$ ) (Corning Incorporated, Corning, NY, USA) at a density of $3 \times 10^{5}$ cells $\mathrm{mL}^{-1}{ }^{24}$ The culture medium $(0.5 \mathrm{~mL}$ in the apical and $1.5 \mathrm{~mL}$ in the basolateral compartment) was changed every 48 hours. Only cell monolayers with a transepithelial electrical resistance of $>350 \Omega \mathrm{cm}^{2}$ were used for transport experiments. After cell culture in a 12 -well Transwell ${ }^{\circledR}$ (Corning Incorporated) plate for 21-29 days, the culture medium was removed using filters and the monolayer was preincubated with $0.5 \mathrm{~mL}$ of Hanks' balanced salt solution (HBSS) for 20 minutes at $37^{\circ} \mathrm{C}$. The transepithelial electrical resistance was measured, and the HBSS was then removed using filters. A total of $0.5 \mathrm{~mL}$ of rhPTH (1-34) or PTH/LysDOCA complex solution in HBSS $(200 \mu \mathrm{M})$ was added to the filters, and a sample $\left(C_{0}\right)$ was immediately taken from the apical compartment. During incubation at $37^{\circ} \mathrm{C}, 200 \mu \mathrm{L}$ samples were taken from the basolateral compartment at 0.5 hour, 1 hour, 2 hours, 3 hours, 4 hours, and 5 hours. The samples were filtered through a membrane filter $(0.45 \mu \mathrm{m}, \mathrm{PVDF})$ and stored at $4^{\circ} \mathrm{C}$ for analysis. The concentration of rhPTH (1-34) or PTH/LysDOCA complex that had permeated the monolayer was determined by HPLC analysis. Aliquots $(50 \mu \mathrm{L})$ from each sample were injected into the HPLC system equipped with a Kromasil C18 column $(250 \times 4.6 \mathrm{~mm}, 5 \mu \mathrm{m})$. These were eluted in the mobile phase, $0.1 \%(\mathrm{w} / \mathrm{v})$ trifluoroacetic acid with $76 \%$ to $51 \%$ linear gradient of acetonitrile containing $0.1 \%(\mathrm{w} / \mathrm{v})$ trifluoroacetic acid for 25 minutes at a flow rate of $1.0 \mathrm{~mL} \mathrm{~min}^{-1}$. The peaks of rhPTH (1-34) and PTH/LysDOCA complex were determined at $220 \mathrm{~nm}$ using background subtraction, and the apparent permeability coefficients $\left(P_{\text {app }}\right)$ of rhPTH (1-34) and the PTH/LysDOCA complex were calculated according to the following equation:

$$
P_{\text {app }}=\mathrm{d} Q / \mathrm{d} t \times 1 /\left(A \times C_{0}\right)
$$

where $\mathrm{d} Q / \mathrm{d} t$ indicates the linear appearance rate of mass in the basolateral sides $\left(\mu \mathrm{moL} \mathrm{h}{ }^{-1}\right), C_{0}$ is the initial concentration of rhPTH (1-34) or PTH/LysDOCA complex on the apical side $(\mu \mathrm{M})$, and $A$ is the surface area of the monolayer $\left(\mathrm{cm}^{2}\right)$. 


\section{Pharmacokinetic study in rats}

Ethical approval for this study was obtained from the Institutional Animal Care and Use Committee (IACUC) of Seoul National University. The animal experiments were performed in accordance with the NIH Guidelines for the Care and Use of Laboratory Animals and the guidelines of the IACUC.

Sprague Dawley rats (females, 200-250 g) were purchased from Orient Co., Ltd. (Gyunggi-do, Republic of Korea). The rats were anesthetized via intraperitoneal injection of ketamine $\left(45 \mathrm{mg} \mathrm{kg}^{-1}\right)$ and xylazine $\left(5 \mathrm{mg} \mathrm{kg}^{-1}\right) .{ }^{25} \mathrm{The}$ abdomen of the anesthetized rats was opened to take out the small intestine, and $400 \mu \mathrm{L}$ of solution containing rhPTH (1-34) $\left(0.1 \mathrm{mg} \mathrm{kg}^{-1}\right)$ or PTH/LysDOCA complex (equivalent to $0.1 \mathrm{mg} \mathrm{kg}^{-1}$ of rhPTH [1-34]) was administered into the proximal jejunum. To evaluate relative bioavailability, $150 \mu \mathrm{L}$ of rhPTH (1-34) $\left(0.02 \mathrm{mg} \mathrm{kg}^{-1}\right)$ in sterile water was subcutaneously injected. After administration, blood samples $(200 \mu \mathrm{L})$ were collected at the scheduled time points and immediately mixed with $50 \mu \mathrm{L}$ of sodium citrate $(3.8 \%$ solution). These were then centrifuged $(2,500 \times g, 15$ minutes, $4^{\circ} \mathrm{C}$ ), and the isolated plasma samples were stored at $-70^{\circ} \mathrm{C}$ for analysis. The plasma concentration of rhPTH (1-34) was determined using a human PTH (1-34) ELISA kit (ALPCO Diagnostics, Salem, NH, USA) at $620 \mathrm{~nm}$. Pharmacokinetic parameters were estimated by the noncompartment method using the WinNonlin ${ }^{\circledR}$ software (Version 5.3; Pharsight Corporation, Princeton, NJ, USA).

\section{Preparation of PTH/LysDOCA-loaded enteric microparticles using coaxial ultrasonic atomization}

Enteric microparticles containing either rhPTH (1-34) or the PTH/LysDOCA complex were produced using a coaxial ultrasonic atomizer (Sono-Tek Corp., Milton, NY, USA). rhPTH (1-34) or PTH/LysDOCA complex was dissolved in water $(0.05 \mathrm{~g}$ in $5 \mathrm{~mL}){ }^{26}$ This was dispersed in $95 \mathrm{~g}$ of Eudragit L100-55 solution ( $\left.4 \mathrm{mg} \mathrm{mL}^{-1}\right)$ in a solvent mixture of ethanol and acetone $(30: 60, \mathrm{w} / \mathrm{w})$. The resultant suspension and $4 \mathrm{mg} \mathrm{mL}^{-1}$ of Eudragit L100-55 in a solvent mixture of ethanol and acetone $(32: 64, \mathrm{w} / \mathrm{w})$ were separately delivered into the inner inlet (top feed channel) and outer inlet (side feed channel) via syringe pumps, at flow rates of $0.5 \mathrm{~mL} \mathrm{~min}^{-1}$ and $1.5 \mathrm{~mL} \mathrm{~min}^{-1}$, respectively. To generate fluorescent images using confocal microscopy, $0.05 \%(\mathrm{w} / \mathrm{w})$ of fluorescein isothiocyanate-labeled dextran and rhodamine isothiocyanate were added to the inner suspension and outer enteric polymer coating solution, respectively. Microdroplets formed by atomizer vibrations at a frequency of $120 \mathrm{kHz}$ were collected in liquid paraffin containing $1 \%$ Span 80 with continuous stirring at $350 \mathrm{rpm}$. The resulting solutions were stirred at $800 \mathrm{rpm}$ for 3 hours to solidify enteric microparticles. The enteric microparticles were then harvested by vacuum filtration, washed four times with $n$-hexane, and dried at room temperature.

The size of the microparticles was measured using a laser diffraction particle size analyzer (Mastersizer X; Malvern Instruments). In addition, the surface morphology and distribution of rhPTH (1-34) and the PTH/LysDOCA complex in the microparticles were examined using scanning electron microscopy (JSM-5300; JEOL) and confocal laser scanning microscopy using an argon/HeNe laser and a Zeiss Axio Observer inverted microscope (LSM 710 NLO and LSM 780 NLO; Carl Zeiss Meditec AG, Jena, Germany). Confocal fluorescent images of fluorescein isothiocyanate labeled-dextran and rhodamine isothiocyanate were generated using a $20 \times$ objective lens and excitation at $488 \mathrm{~nm}$ and $568 \mathrm{~nm}$, respectively.

Dissolution tests were performed in $500 \mathrm{~mL}$ of medium containing $0.1 \mathrm{~N} \mathrm{HCl}$ solution ( $\mathrm{pH} 1.2$ ) or phosphate buffer (pH 6.8) at $37^{\circ} \mathrm{C} \pm 0.2^{\circ} \mathrm{C}$, using the USP type 1 apparatus (basket) rotating at $100 \mathrm{rpm}$. The enteric microparticles containing rhPTH (1-34) or the PTH/LysDOCA complex were encapsulated in hard gelatin capsules. Each capsule containing rhPTH (1-34) or PTH/LysDOCA complex was equivalent to $50 \mathrm{mg}$ of rhPTH (1-34). These were subjected to a dissolution test, and $3 \mathrm{~mL}$ samples were withdrawn at 15 minutes, 30 minutes, 45 minutes, 60 minutes, 90 minutes, and 120 minutes. After filtration, the amount of rhPTH (1-34) or the PTH/LysDOCA complex in the samples was quantified by HPLC using a UV detector, as described above.

\section{Ovariectomized rat model}

Antiosteoporotic effects of the orally administered rhPTH (1-34) and the LysDOCA complex were evaluated in 60 Sprague Dawley rats (female, 8 weeks old). Bilateral ovariectomy was performed in 50 rats to induce osteoporosis, and sham surgeries without ovary removal (SHAM) were conducted in ten rats. After 2 weeks, the ovariectomized (OVX) rats were randomly assigned to five groups of eight rats each as follows: OVX (without drug administration), OVX-PTH-SC (once-daily subcutaneous injection of $10 \mu \mathrm{g} \mathrm{kg}^{-1} \mathrm{rhPTH}$ [1-34]), OVX-PTH-ORAL (once-daily oral administration of $50 \mu \mathrm{g} \mathrm{kg}^{-1} \mathrm{rhPTH}$ [1-34] after $200 \mu \mathrm{L}$ of an aqueous antacid solution containing $3 \% \mathrm{Mg}(\mathrm{OH})_{2}$ ), OVXPTH/LysDOCA-ORAL (once-daily oral administration of rhPTH [1-34]/LysDOCA complex as $50 \mu \mathrm{g} \mathrm{kg}^{-1} \mathrm{rhPTH}$ [1-34] after $200 \mu \mathrm{L}$ of an aqueous antacid solution containing $\left.3 \% \mathrm{Mg}(\mathrm{OH})_{2}\right)$, and OVX-PTH/LysDOCA-MP-ORAL 
(once-daily oral administration of enteric microparticles containing PTH/LysDOCA complex as $50 \mu \mathrm{g} \mathrm{kg}^{-1} \mathrm{rhPTH}$ [1-34]). Over the course of the treatments, the volume of each dose was adjusted to accommodate daily body weights. Twelve weeks after the treatments began, the left and right tibiae were removed from the sacrificed rats and fixed in neutral buffered $4 \%$ formalin.

\section{Microcomputed tomography scanning and histological observation of tibiae}

Tibiae were scanned to evaluate their microarchitecture and to measure the structural parameters and bone mineral density (BMD) using an in vivo microcomputed tomography ( $\mu$-CT, Skyscan 1076; Bruker Corporation, Billerica, MA, USA). ${ }^{27}$ The X-ray source settings were as follows: voltage of $100 \mathrm{kV}$, current of $100 \mu \mathrm{A}$, and beam filtration through a $1.0 \mathrm{~mm}$-thick aluminum filter. Two-dimensional projections were recorded every $0.5^{\circ}$ rotation step from $0^{\circ}$ to $360^{\circ}$, with a scanning width of $35 \mathrm{~mm}$ and height of $17 \mathrm{~mm}$. Threedimensional (3D) microstructural images were reconstructed using a modified Feldkamp back-projection algorithm. After reconstruction, the images were low-pass-filtered (Gaussian filter) and subjected to global thresholding at the fixed range of 0.0 to 0.04 cross section to extract the mineral phase. Trabecular bone was extracted from the whole image by semiautomatic contouring using the CT-Analyzer 1.13 (Bruker Corporation). For detailed analysis and quantification of trabecular bone, a volume of interest (VOI) was defined as the distal metaphysis of the tibia. The VOI is $1.8 \mathrm{~mm}$ below $0.54 \mathrm{~mm}$ from proximal growth plate in the tibia. The following structural parameters were calculated: BMD, bone volume fraction (BV/TV), bone surface/volume ratio (BS/BV), trabecular thickness (Tb.Th), trabecular separation (Tb.Sp), trabecular number (Tb.N), trabecular pattern factor (Tb.Pf), and structural model index (SMI).

The cortical bone was also evaluated in the diaphysis of the tibia. The VOI for analysis of the cortical bone was $0.9 \mathrm{~mm}$ below $0.54 \mathrm{~mm}$ from the end point of the VOI of the trabecular bone in the tibia. The structural parameters for the cortical bone, such as cortical bone mineral density (Ct.BMD), cortical bone volume (Ct.BV), cortical thickness (Ct.Th), and mean polar moment of inertia (MMI [polar]), were determined.

For histological observation, the formalin-fixed tibiae were decalcified in $10 \%$ ethylenediaminetetraacetic acid and dehydrated using a graded series of ethanol treatments. They were then embedded in paraffin wax blocks, sectioned at $5 \mu \mathrm{m}$ thickness, and stained with hematoxylin and eosin (H\&E). The histological sections were observed under an optical microscope (Bx41; Olympus Corporation, Tokyo, Japan), and photographs were taken by focusing on the central part of the growth plate.

\section{Statistical analyses}

All data are expressed as mean \pm standard deviation. A $P$-value of $<0.05$ was considered to indicate statistical significance. Comparisons between groups were made using a $t$-test between two mean values for unpaired data, or a one-way analysis of variance followed by Tukey's multiple-comparison tests among three or more mean values for unpaired data.

\section{Results \\ Preparation and characterization of PTH/ LysDOCA complex}

PTH (1-34) nanoparticles were formed by making a complex between rhPTH (1-34) and LysDOCA. The secondary structure of the PTH/LysDOCA complex was characterized by CD spectroscopy in the presence of water or $20 \%$ TFE. Nadirs at 208 and $222 \mathrm{~nm}$ in the presence of TFE showed that LysDOCA in the PTH/LysDOCA complex did not affect the secondary structure of PTH (1-34) (Figure 1). This was consistent with the CD spectra of PTH (1-34) and PTH/ LysDOCA in the presence of water. Because the relatively stable $\alpha$-helical segments in the secondary structure of PTH (1-34) are important for receptor binding and activation of PTH (1-34), the retention of secondary structure in
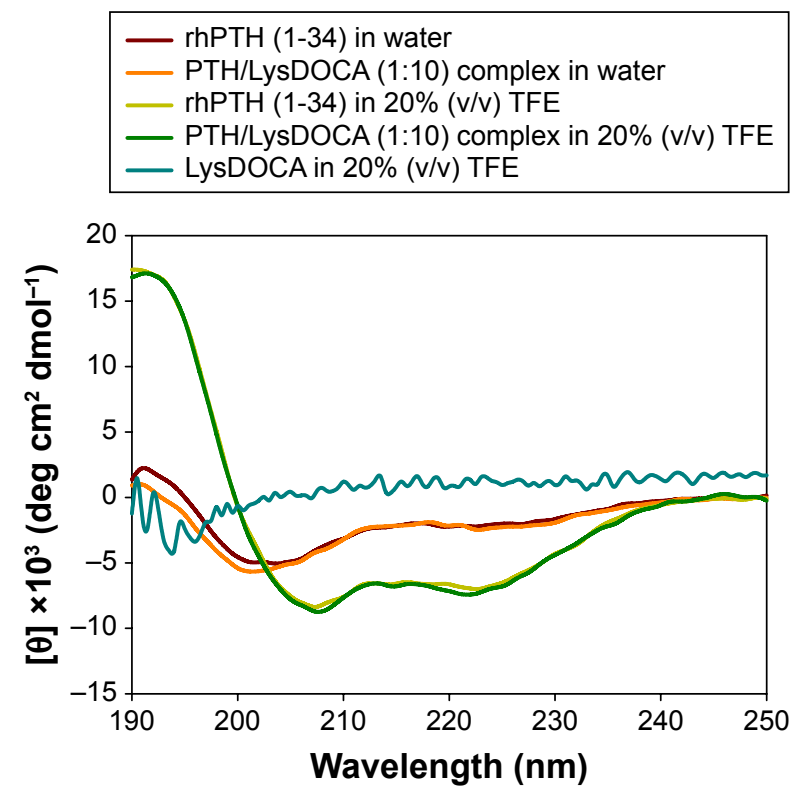

Figure I Circular dichroism (CD) spectra of rhPTH (I-34), LysDOCA, and PTH/ LysDOCA ( $1: 10)$ nanocomplex at a concentration of $10 \mu \mathrm{M}$ in water or in $20 \%(\mathrm{v} / \mathrm{v})$ 2,2,2-trifluoroethanol (TFE) aqueous solution.

Abbreviations: rhPTH, recombinant human parathyroid hormone; LysDOCA, lysine-linked deoxycholic acid. 
the PTH/LysDOCA complex may be significant for the bioactivity of PTH (1-34). ${ }^{28}$

The formation of nanocomplexes was confirmed by dynamic light-scattering and TEM. The complex between amphiphilic LysDOCA and rhPTH (1-34) had a particle size of $33.0 \pm 3.36 \mathrm{~nm}$ and a zeta potential of $2.85 \pm 0.11$. When the feed molar ratios of rhPTH (1-34) to LysDOCA were $1: 10(>1: 5)$, the negative surface charge of rhPTH (1-34) was neutralized by association with the positively charged LysDOCA (6.27 \pm 1.29$)$, as measured by the zeta potential of $-14.0 \pm 1.35$. This is consistent with the observation that at least five negatively charged amino acids on the rhPTH (1-34) chain can interact electrostatically with LysDOCA. TEM images of the negatively stained PTH/LysDOCA complexes revealed regular and well-defined spherical nanoparticles, while the rhPTH (1-34) formed aggregates of varying size (Figure 2).

\section{In vitro bioactivity of PTH/LysDOCA nanocomplex}

The evaluation of in vitro bioactivity involved measuring the cAMP levels in MC3T3-E1 cell lysates. The ability of both rhPTH (1-34) and the PTH/LysDOCA (1:10) nanocomplex to stimulate cAMP production in the PTH receptor-expressing cells was assessed. Within the concentration range $0.01-1.0 \mu \mathrm{M}$, the PTH receptor-mediated cAMP production in response to the $\mathrm{PTH} / \mathrm{LysDOCA}$ nanocomplex was comparable with that of rhPTH (1-34) (Figure 3). This is consistent with an intact secondary structure, as revealed by the CD spectrum of the PTH/LysDOCA nanocomplex. A concentration of $1.0 \mu \mathrm{M}$ PTH/LysDOCA nanocomplex induced $\sim 5.7$-fold higher intracellular cAMP accumulation in differentiated osteoblasts than stimulation with $0.01 \mu \mathrm{M}$ of the PTH/LysDOCA nanocomplex. In contrast, the cAMP level decreased upon treatment with $10 \mu \mathrm{M}$ or $100 \mu \mathrm{M}$ of
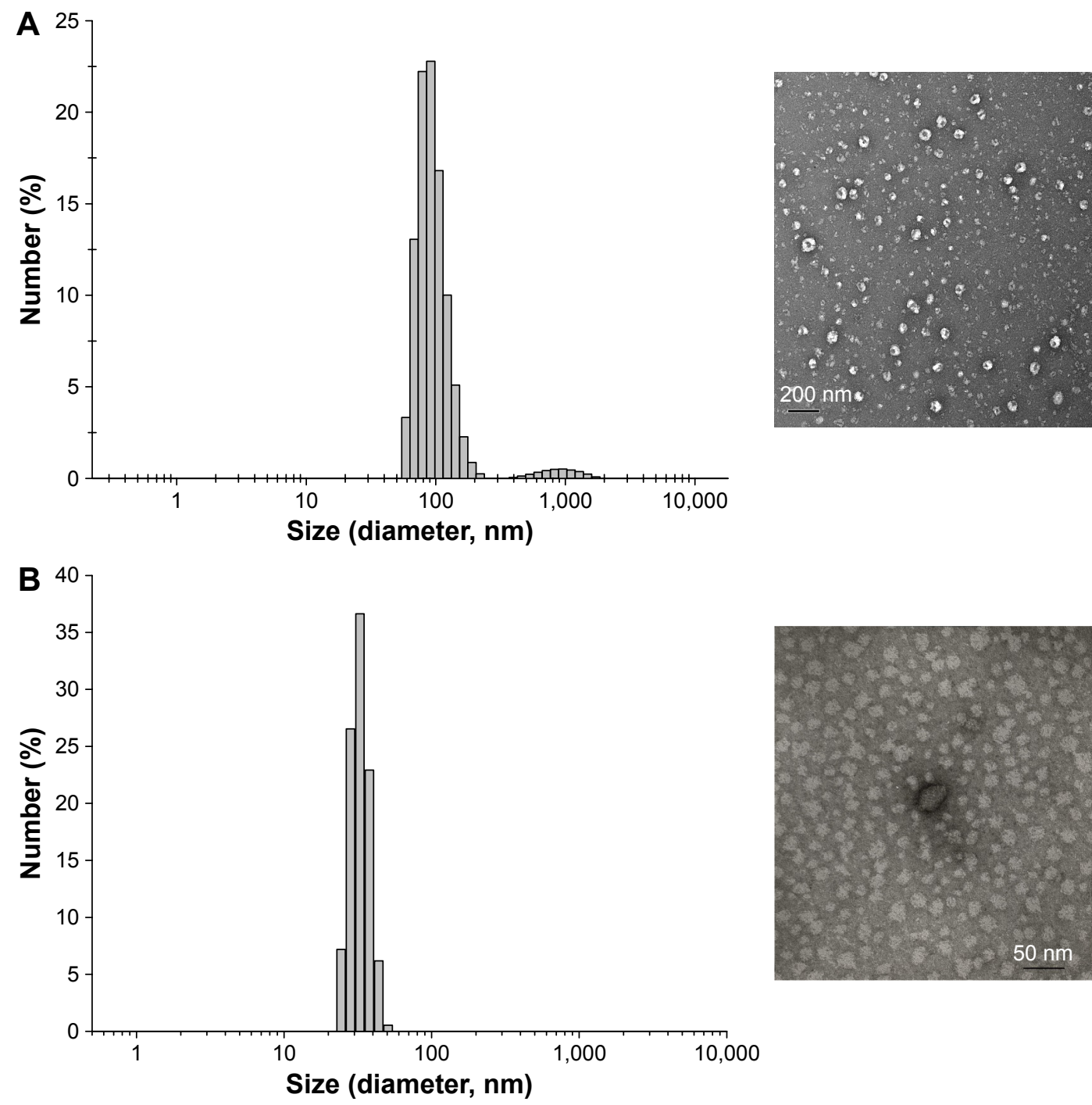

Figure 2 Particle size distribution and transmission electron micrographs of rhPTH (I-34) (A) and PTH/LysDOCA (I:I0) nanocomplex (B). Abbreviations: rhPTH, recombinant human parathyroid hormone; LysDOCA, lysine-linked deoxycholic acid. 


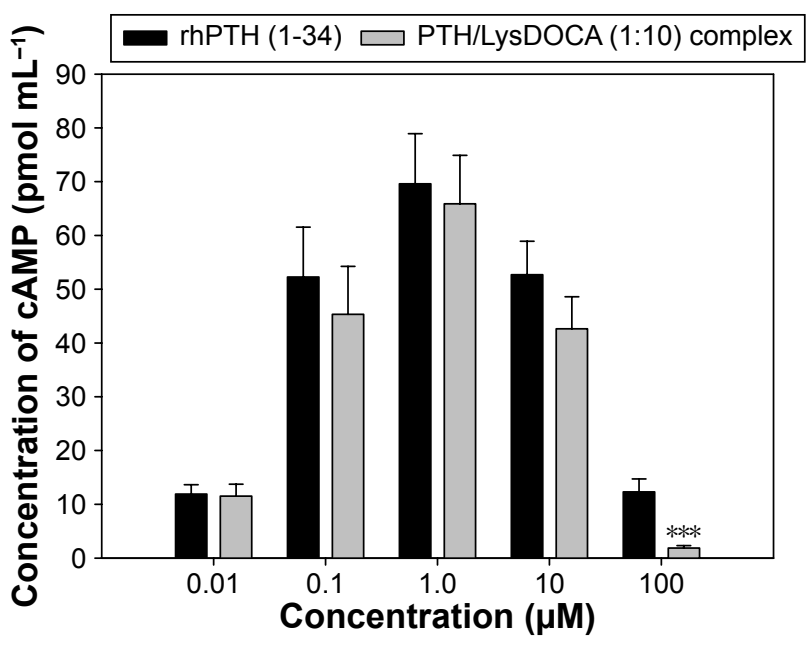

Figure 3 Intracellular cyclic adenosine monophosphate (cAMP) content after incubation of MC3T3-EI cells with rhPTH (I-34) or PTH/LysDOCA (I:I0) nanocomplex.

Note: Each value represents the mean \pm standard deviation ( $n=5$ for each group). $* * * P<0.00$ I compared with rhPTH (I-34).

Abbreviations: rhPTH, recombinant human parathyroid hormone; LysDOCA, lysine-linked deoxycholic acid.

rhPTH (1-34) or PTH/LysDOCA nanocomplex compared with treatment using $1.0 \mu \mathrm{M}$.

\section{In vitro permeability across Caco-2 cell monolayer and in vivo intestinal absorption in rats}

We also investigated the in vitro permeability of rhPTH (1-34) and the PTH/LysDOCA nanocomplex across a Caco-2 cell monolayer. When the feed molar ratio of rhPTH (1-34) to LysDOCA was increased from 1:1 to $1: 10, P_{\text {app }}$ increased from $2.93 \pm 1.09 \times 10^{-7} \mathrm{~cm} \mathrm{~s}^{-1}$ to $10.4 \pm 2.41 \times 10^{-7} \mathrm{~cm} \mathrm{~s}^{-1}$ (Table 1). As the molar ratio of the complex between LysDOCA and rhPTH (1-34) was increased to values $>5$, the permeability of rhPTH (1-34) was significantly enhanced

Table I In vitro permeabilities of rhPTH (I-34) and PTH/ LysDOCA complexes

\begin{tabular}{ll}
\hline Test material & $\begin{array}{l}\text { Apparent permeability } \\
\left(\boldsymbol{P}_{\text {app }}, \mathbf{c m ~ s}^{-1}\right)^{\mathbf{a}}\end{array}$ \\
\hline rhPTH $(I-34)$ & $3.62 \pm 0.45 \times 10^{-7 b, c}$ \\
PTH/LysDOCA (I:I) complex & $2.93 \pm 1.09 \times 10^{-7 b, c}$ \\
PTH/LysDOCA (I:3) complex & $4.12 \pm 0.76 \times 10^{-7 c, d}$ \\
PTH/LysDOCA (I:5) complex & $7.35 \pm I .12 \times 10^{-7 e}$ \\
PTH/LysDOCA (I:I0) complex & $10.4 \pm 2.41 \times 10^{-7}$ \\
\hline
\end{tabular}

Notes: Statistics: one-way ANOVA followed by Tukey's multiple-comparison test. apparent permeability coefficient $\left(P_{\text {app }}\right)$ of rhPTH (I-34) and PTH/ LysDOCA nanocomplex through a Caco-2 cell monolayer. Each value represents the mean \pm standard deviation $(n=6)$. ${ }^{b} P<0.001$ compared with the $\mathrm{PTH} / \mathrm{LysDOCA}$ (I:5) complex. ${ }^{c} P<0.001$ compared with the PTH/LysDOCA $(I: 10)$ complex. d $P<0.0$ I compared with the PTH/LysDOCA (I:5) complex. ${ }^{e} P<0.01$ compared with the PTH/LysDOCA (I:I0) complex.

Abbreviations: rhPTH, recombinant human parathyroid hormone; LysDOCA, lysine-linked deoxycholic acid; ANOVA, analysis of variance. compared with that of free rhPTH (1-34). A 1:10 molar ratio of rhPTH (1-34) to LysDOCA enhanced the apical-tobasal $P_{\text {app }}$ of the PTH/LysDOCA complex across a Caco-2 cell monolayer by 2.87 -fold compared with rhPTH (1-34) alone $\left(10.4 \pm 2.41 \times 10^{-7} \mathrm{~cm} \mathrm{~s}^{-1}\right.$ vs $\left.3.62 \pm 0.45 \times 10^{-7} \mathrm{~cm} \mathrm{~s}^{-1}\right)$. We therefore performed further studies with the PTH/LysDOCA $(1: 10)$ complex to assess its in vivo intestinal absorption and antiosteoporotic effect in rats.

In the in vivo intestinal absorption study in rats, the PTH (1-34) concentrations in the plasma versus time profiles following administration are illustrated in Figure 4. After intrajejunal administration of $0.1 \mathrm{mg} \mathrm{kg}^{-1} \mathrm{rhPTH}(1-34)$ alone, the maximum plasma concentration $\left(C_{\max }\right)$ was $39.16 \pm 19.80 \mathrm{pg} \mathrm{mL}^{-1}$, the area under the plasma concentration versus time curve $\left(\mathrm{AUC}_{\text {last }}\right)$ was 1,853.2 $\pm 1,491.8 \mathrm{pg}$ min $\mathrm{mL}^{-1}$, and the relative bioavailability compared with the subcutaneous dose was $1.06 \% \pm 0.85 \%$. In contrast, when compared with intrajejunal administration of rhPTH (1-34) alone, the intrajejunal PTH/LysDOCA (1:10) nanocomplex (equivalent to $0.1 \mathrm{mg} \mathrm{kg}^{-1} \mathrm{rhPTH}$ [1-34]) yielded an 11.16-fold increase in $C_{\max }\left(437.1 \pm 107.2 \mathrm{pg} \mathrm{mL}^{-1}\right)$, a 16.26 -fold increase in $\mathrm{AUC}_{\text {last }}$ $\left(30,133 \pm 11,243 \mathrm{pg}\right.$ min $\left.\mathrm{mL}^{-1}\right)$, and a 16.20 -fold increase in relative bioavailability versus the subcutaneous route $(17.2 \% \pm 6.41 \%)$ (Table 2$)$. Therefore, intestinal permeability and absorption of rhPTH (1-34) in rats were significantly enhanced by the formation of a complex with LysDOCA. In addition, $T_{\max }$ was $15.0 \pm 0.0$ minutes, $30.0 \pm 0.0$ minutes, or 35.0 \pm 8.7 minutes after subcutaneous or intrajejunal administration of rhPTH (1-34) or PTH/LysDOCA complex,

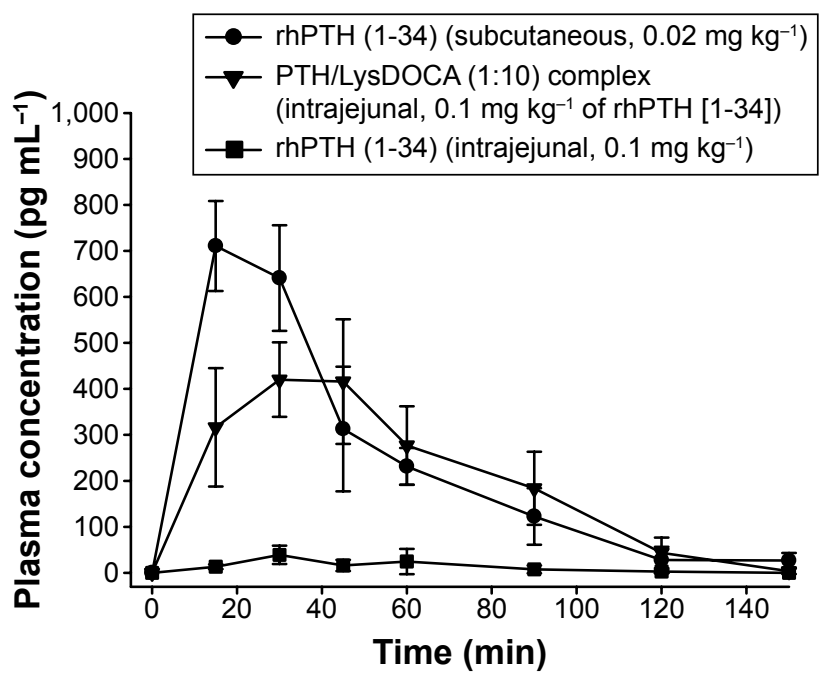

Figure 4 Venous plasma concentration versus time profiles of rhPTH (I-34) after a single subcutaneous administration of rhPTH (I-34) $\left(0.02 \mathrm{mg} \mathrm{kg}^{-1}\right)$ and intrajejunal administration of rhPTH (I-34) $\left(0.1 \mathrm{mg} \mathrm{kg}^{-1}\right)$ or PTH/LysDOCA (I:I0) nanocomplex (equivalent to $0.1 \mathrm{mg} \mathrm{kg}^{-1}$ of rhPTH [1-34]) to rats.

Note: Each value represents the mean \pm standard deviation ( $n=4$ for each group). Abbreviations: rhPTH, recombinant human parathyroid hormone; LysDOCA, lysine-linked deoxycholic acid; min, minutes. 
Table 2 Pharmacokinetic parameters after intrajejunal administration of rhPTH (I-34) or PTH/LysDOCA (I:I0) nanocomplex

\begin{tabular}{|c|c|c|c|}
\hline Test material & rhPTH (I-34) & rhPTH (I-34) & PTH/LysDOCA $(1: 10)$ nanocomplex \\
\hline Administration & Subcutaneous & Intrajejunal & Intrajejunal \\
\hline Dose of rhPTH (I-34) $\left(\mathrm{mg} \mathrm{kg}^{-1}\right)$ & 0.02 & 0.1 & 0.1 \\
\hline$T_{\max }(\min )$ & $15 \pm 0.00$ & $30 \pm 0.00$ & $35 \pm 8.7$ \\
\hline$C_{\max }^{\max }\left(\mathrm{pg} \mathrm{mL^{-1 } )}\right.$ & $710.8 \pm 97.75$ & $39.16 \pm 19.80$ & $437.1 \pm 107.2$ \\
\hline$A \cup C_{\text {last }}\left(p g \min \mathrm{mL}^{-1}\right)$ & $35,108 \pm 9,077.7$ & 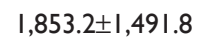 & $30,133 \pm 11,243$ \\
\hline$A \cup C_{\text {inf }}\left(\mathrm{pg} \min \mathrm{mL}^{-1}\right)$ & $36,161 \pm 9,843.9$ & $2,688.9 \pm 1,299.6$ & $30,790 \pm 11,219$ \\
\hline Bioavailability (\%) & 100 & $1.06 \pm 0.85$ & $|7.2 \pm 6.4|$ \\
\hline
\end{tabular}

Notes: Each value represents the mean \pm standard deviation $(n=4)$. Bioavailability, $\left(\mathrm{AUC}_{\text {last, intraiejual }} / \mathrm{Dose}_{\text {rhPTH (I-34), intrajejunal }}\right) /\left(\mathrm{AUC}_{\text {last, subcutaneous }} / \mathrm{Dose}_{\text {rhPTH (I-34) subcutaneous }}\right) \times 100$.

Abbreviations: rhPTH, recombinant human parathyroid hormone; LysDOCA, lysine-linked deoxycholic acid; $T_{\max }$, time to reach $C_{\max } ; C_{\max }$, maximum plasma concentration; $A \cup C_{\text {last }}$, area under the plasma concentration versus time curve from zero to the time of the last measurable plasma concentration; $A U C_{\text {inf }}$ area under the plasma concentration versus time curve from zero to infinity.

respectively, and the plasma concentration after intrajejunal administration of PTH/LysDOCA complex was greater than the lower limit for quantification until 120 minutes.

\section{Microencapsulation of PTH/LysDOCA nanocomplexes with enteric polymer by coaxial ultrasonic atomization}

For the oral formulation of rhPTH (1-34), enteric microparticles containing the PTH/LysDOCA nanocomplexes were prepared using coaxial ultrasonic atomization. To design a core-shell structure for the enteric microparticles, we first varied the inner flow rate of the drug solution at a fixed outer flow rate of enteric polymer solution. When the inner flow rate was $<0.5 \mathrm{~mL} \mathrm{~min}^{-1}$, more homogeneous microparticles encapsulating the complex were obtained. The enteric microparticles did not form a core-shell structure at an

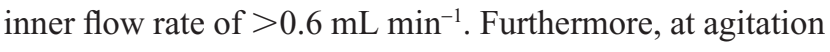
speeds of $>800 \mathrm{rpm}$, better encapsulation and more uniform microparticles with smoother surfaces were generated. Under optimum conditions, the PTH/LysDOCA complexloaded enteric microparticles were encapsulated with $\sim 80 \%$ efficiency and had a mean particle diameter of $60.2 \pm 27.5 \mu \mathrm{m}$ (Figure 5A). The confocal images also indicated that the majority of PTH/LysDOCA complexes were located in the core and uniformly encapsulated within the enteric polymer shell (Figure 5B).

The prepared enteric microparticles were also tested for in vitro dissolution. In a medium with $\mathrm{pH} \mathrm{1.2,} \mathrm{the} \mathrm{enteric}$ microparticles did not disintegrate or dissolve within 120 minutes. In a pH 6.8 buffer, however, $>90 \%$ of rhPTH (1-34) or the PTH/LysDOCA complex was completely released from the enteric microparticles within 120 minutes (Figure 6).
A

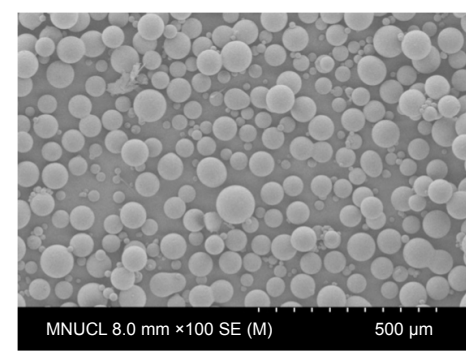

B

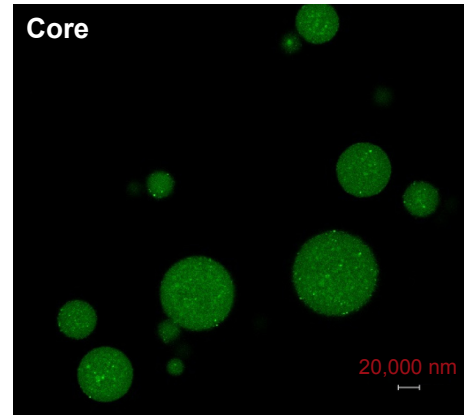

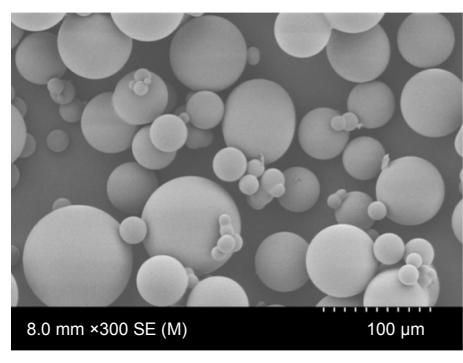
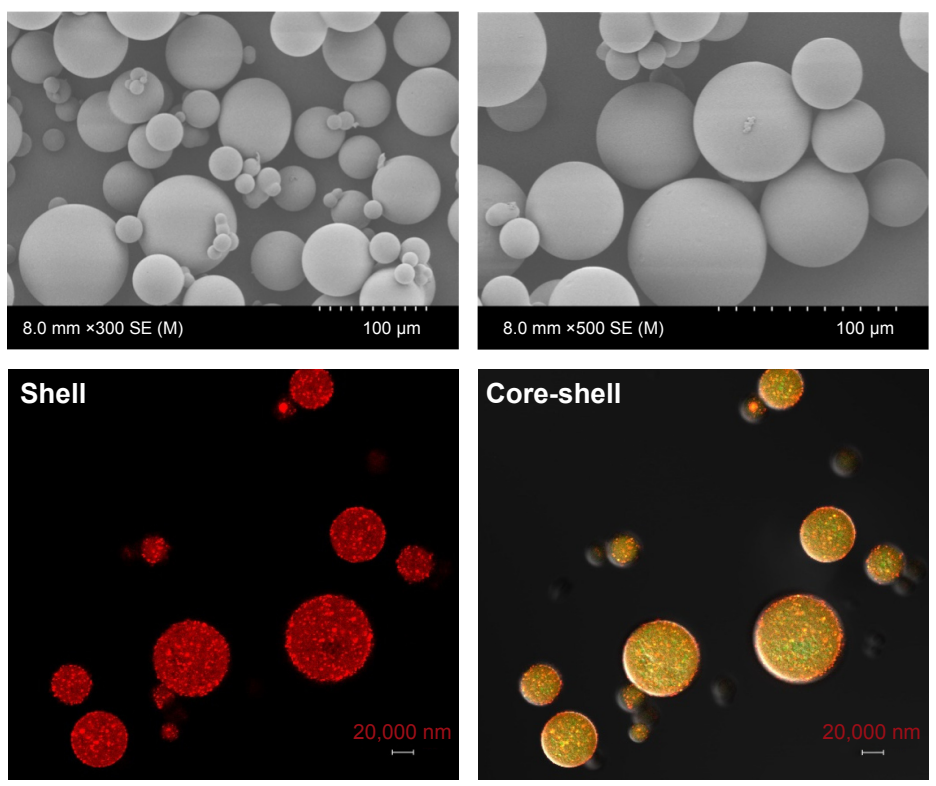

Figure 5 Representative scanning electron microscope (SEM, A) and confocal laser scanning microscopy (CLSM, B) images of PTH/LysDOCA (I:I0) nanocomplex containing enteric microparticles.

Notes: Eudragit LI00-55 polymer shell was mixed with rhodamine isothiocyanate (RITC, in red), and the core containing PTH/LysDOCA (I:I0) nanocomplex was mixed with fluorescein isothiocyanate-labeled dextran (FITC-dextran, in green).

Abbreviations: PTH, parathyroid hormone; LysDOCA, lysine-linked deoxycholic acid. 


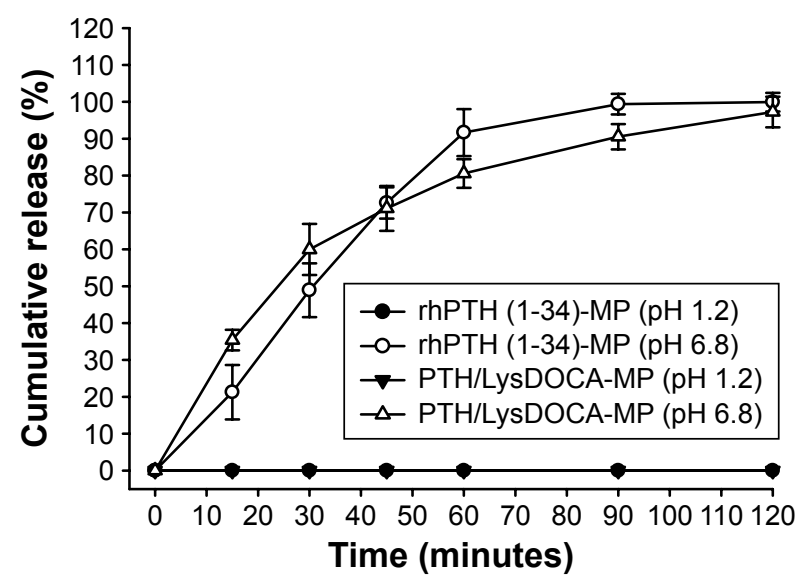

Figure 6 In vitro cumulative percentage release profiles of rhPTH (I-34) or PTH/ LysDOCA ( $\mathrm{I}: \mathrm{I0})$ nanocomplex from the enteric microparticles in $\mathrm{pH} \mathrm{I} .2$ and $\mathrm{pH} 6.8$ media.

Note: Each value represents the mean \pm standard deviation ( $n=6$ for each group). Abbreviations: rhPTH, recombinant human parathyroid hormone; LysDOCA, lysine-linked deoxycholic acid.

\section{In vivo antiosteoporotic effect of PTH/ LysDOCA complex in OVX rats}

The in vivo therapeutic efficacy was assessed in a rat model of postmenopausal osteoporosis. To explore the trabecular microarchitectural properties and calculate the morphometric parameters, we performed in vivo $\mu$-CT measurements. Compared with the SHAM group, the OVX control showed significant decreases in BMD $\left(0.1046 \pm 0.0391 \mathrm{~g} \mathrm{~cm}^{-3}\right.$ vs $\left.0.4885 \pm 0.0414 \mathrm{~g} \mathrm{~cm}^{-3}\right)$, BV/TV $(4.3508 \% \pm 0.9652 \%$ vs $31.0642 \% \pm 2.6533 \%)$, Tb.Th $(0.0721 \pm 0.0047 \mathrm{~mm}$ vs $0.0814 \pm 0.0061 \mathrm{~mm})$, and Tb.N $\left(0.5545 \pm 0.1530 \mathrm{~mm}^{-1}\right.$ vs $3.7966 \pm 0.3036 \mathrm{~mm}^{-1}$ ), with significant increases in BS/ BV $\left(52.3512 \pm 4.3507 \mathrm{~mm}^{-1}\right.$ vs $\left.40.9926 \pm 4.0598 \mathrm{~mm}^{-1}\right)$, Tb.Sp $(0.9234 \pm 0.1556 \mathrm{~mm}$ vs $0.1798 \pm 0.010 \mathrm{~mm})$, Tb.Pf $\left(17.2727 \pm 1.1483 \mathrm{~mm}^{-1}\right.$ vs $\left.2.5354 \pm 2.7166 \mathrm{~mm}^{-1}\right)$, and SMI (2.3973 \pm 0.0899 vs $1.1430 \pm 0.2227$ ) (Figure 7). However,
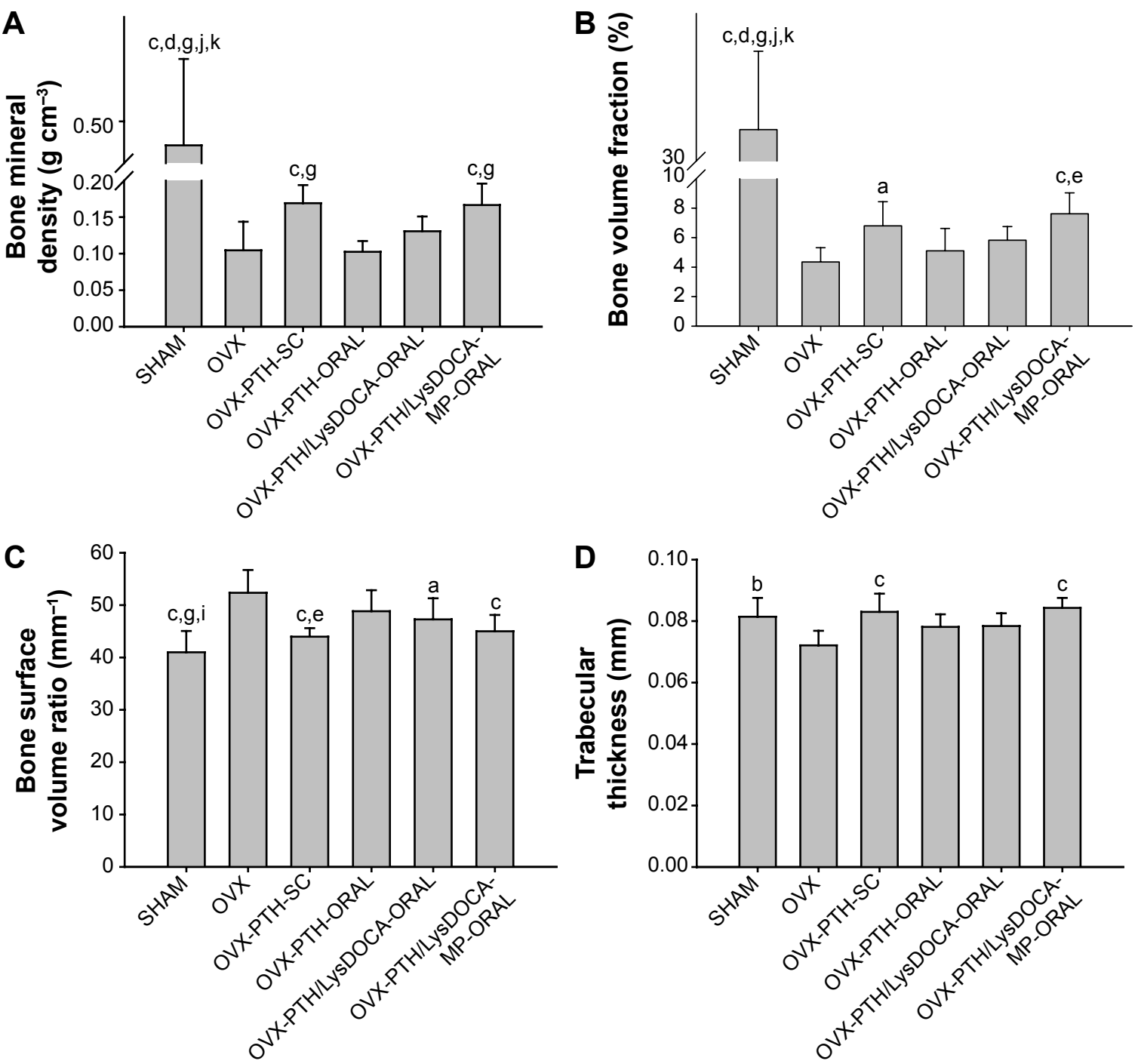

Figure 7 (Continued) 

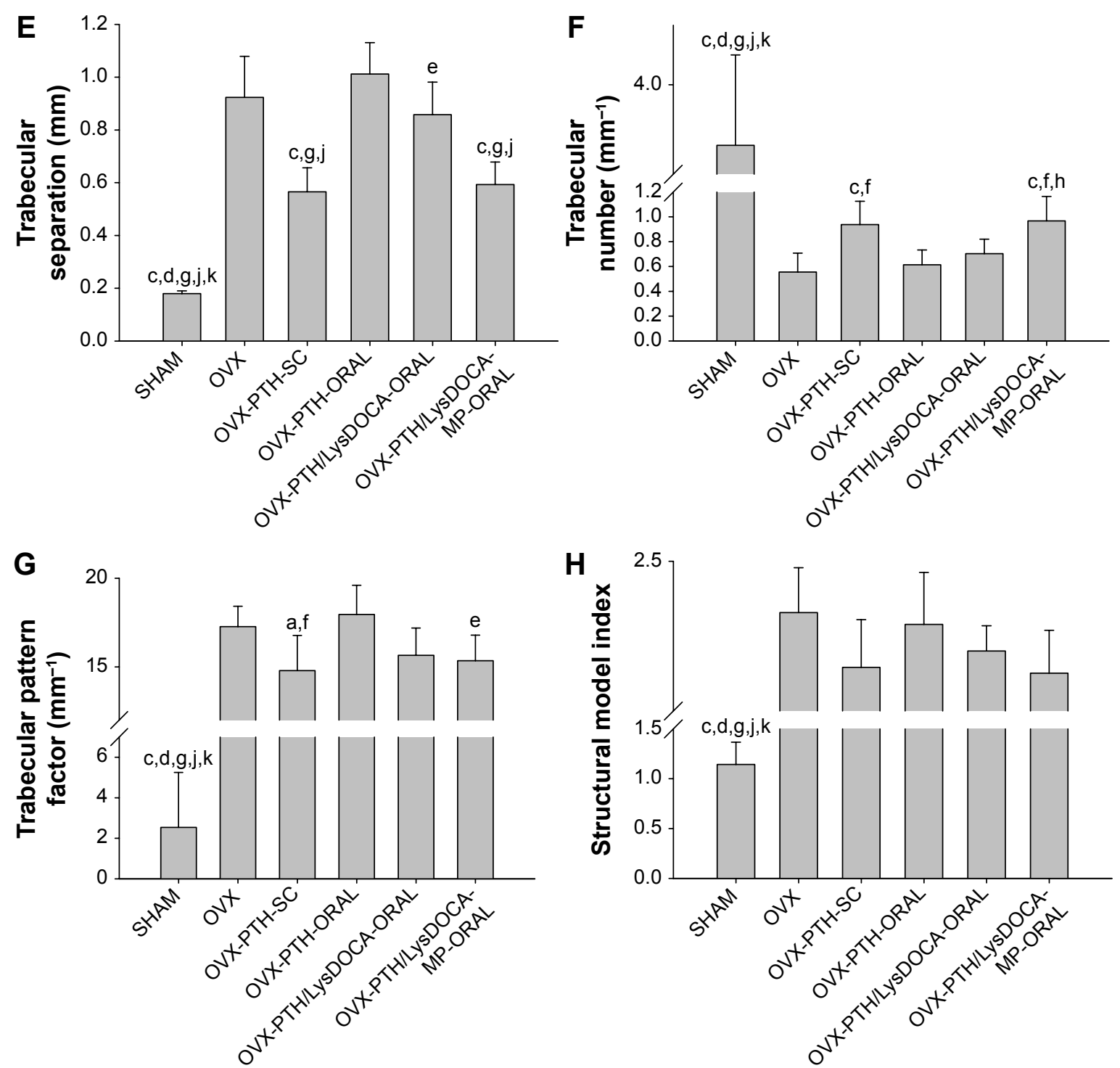

Figure 7 Microcomputed tomography ( $\mu-C T)$ analyses of the tibiae of rats that were either sham-operated (SHAM) or ovariectomized (OVX) and treated with various modes.

Notes: The treatment modes were once-daily subcutaneous injection of $10 \mu \mathrm{g} \mathrm{kg}{ }^{-1}$ rhPTH (I-34) (OVX-PTH-SC) or once-daily oral administration of $50 \mu \mathrm{g}$ kg ${ }^{-1}$ rhPTH (I-34) (OVX-PTH-ORAL), rhPTH (I-34)/Lys-DOCA complex as $50 \mu \mathrm{g} \mathrm{kg-1}$ of rhPTH (I-34) (OVX-PTH/LysDOCA-ORAL), or enteric-microparticles containing rhPTH (I-34)/Lys-DOCA nanocomplex as $50 \mu \mathrm{g} \mathrm{kg}{ }^{-1}$ of rhPTH (I-34) (OVX-PTH/LysDOCA-MP-ORAL) for I2 weeks. Bone mineral density (BMD) (A), bone volume fraction (BV/ TV) (B), bone surface/volume ratio (BS/BV) (C), trabecular thickness (Tb.Th) (D), trabecular separation (Tb.Sp) (E), trabecular number (Tb.N) (F), trabecular pattern factor (Tb.Pf) (G), and structure model index (SMI) (H). Data are presented as mean \pm standard deviation ( $\mathrm{n}=10$ for each group). ${ }^{a} P<0.05$ compared with the $\mathrm{OVX}$ group; ${ }^{\mathrm{b}} \mathrm{P}<0.0 \mathrm{I}$ compared with the OVX group; ${ }^{c P}<0.00$ I compared with the OVX group; ${ }^{d} P<0.001$ compared with the OVX-PTH-SC group; $\mathrm{e}<0.05$ compared with the OVX-PTH-ORAL

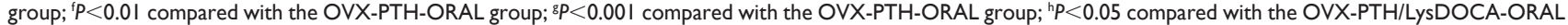

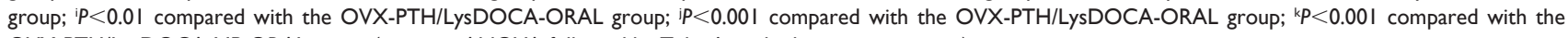
OVX-PTH/LysDOCA-MP-ORAL group (one-way ANOVA followed by Tukey's multiple-comparison test).

Abbreviations: PTH, parathyroid hormone; recombinant human PTH; LysDOCA, lysine-linked deoxycholic acid; ANOVA, analysis of variance.

the decreases in BMD, BV/TV, Tb.Th, and Tb.N in OVX rats were significantly suppressed in the OVX-PTH-SC and OVX-PTH/LysDOCA-MP-ORAL groups. As shown in Figure 7A, the OVX-PTH/LysDOCA-MP-ORAL group (treated with $50 \mu \mathrm{g} \mathrm{kg}^{-1} \mathrm{rhPTH}$ [1-34]) showed a higher BMD (159\%) than did the OVX control $\left(0.1666 \pm 0.0293 \mathrm{~g} \mathrm{~cm}^{-3}\right.$ vs $\left.0.1046 \pm 0.0391 \mathrm{~g} \mathrm{~cm}^{-3}\right)$ at 12 weeks. In contrast, the
OVX-PTH-ORAL group did not show a significant reduction in the loss of BMD observed in OVX rats.

The OVX-PTH/LysDOCA-MP-ORAL group also showed significant improvements in trabecular microarchitecture parameters, similar to the OVX-PTH-SC group: $175 \%$ in BV/TV $(7.6194 \% \pm 1.4202 \%)$ and $174 \%$ in $\mathrm{Tb} . \mathrm{N}$ $\left(0.9673 \pm 0.1968 \mathrm{~mm}^{-1}\right)$ compared with the OVX control. In 
contrast, the OVX-PTH-ORAL group did not show a significant reduction in the loss of $\mathrm{BV} / \mathrm{TV}$ and Tb.N observed in OVX rats. In addition, increases in Tb.Sp, Tb.Pf, and SMI in OVX rats were significantly suppressed in the OVX-PTH-SC and OVX-PTH/LysDOCA-MP-ORAL groups, but not in the OVX-PTH-ORAL group.

Evaluation of the cortical bone in the midshaft region of tibia using $\mu$-CT is shown in Figure 8. After a 12-week treatment, all parameters in the OVX control group were significantly reduced compared with those in the SHAM group: 97\% lower Ct.BMD, 88\% lower Ct.BV, 96\% lower Ct.Th, and 77\% lower MMI (polar). Conversely, the OVXPTH/LysDOCA-MP-ORAL group showed 103\%, 114\%, 107\%, and 131\% higher Ct.BMD, Ct.BV, Ct.Th, and MMI (polar), respectively, compared with the OVX control group. Compared with the OVX-PTH-ORAL group, Ct.BMD, Ct.BV, Ct.Th, and MMI (polar) were 103\%, 115\%, 109\%, and $135 \%$ higher in the OVX-PTH/LysDOCA-MP-ORAL
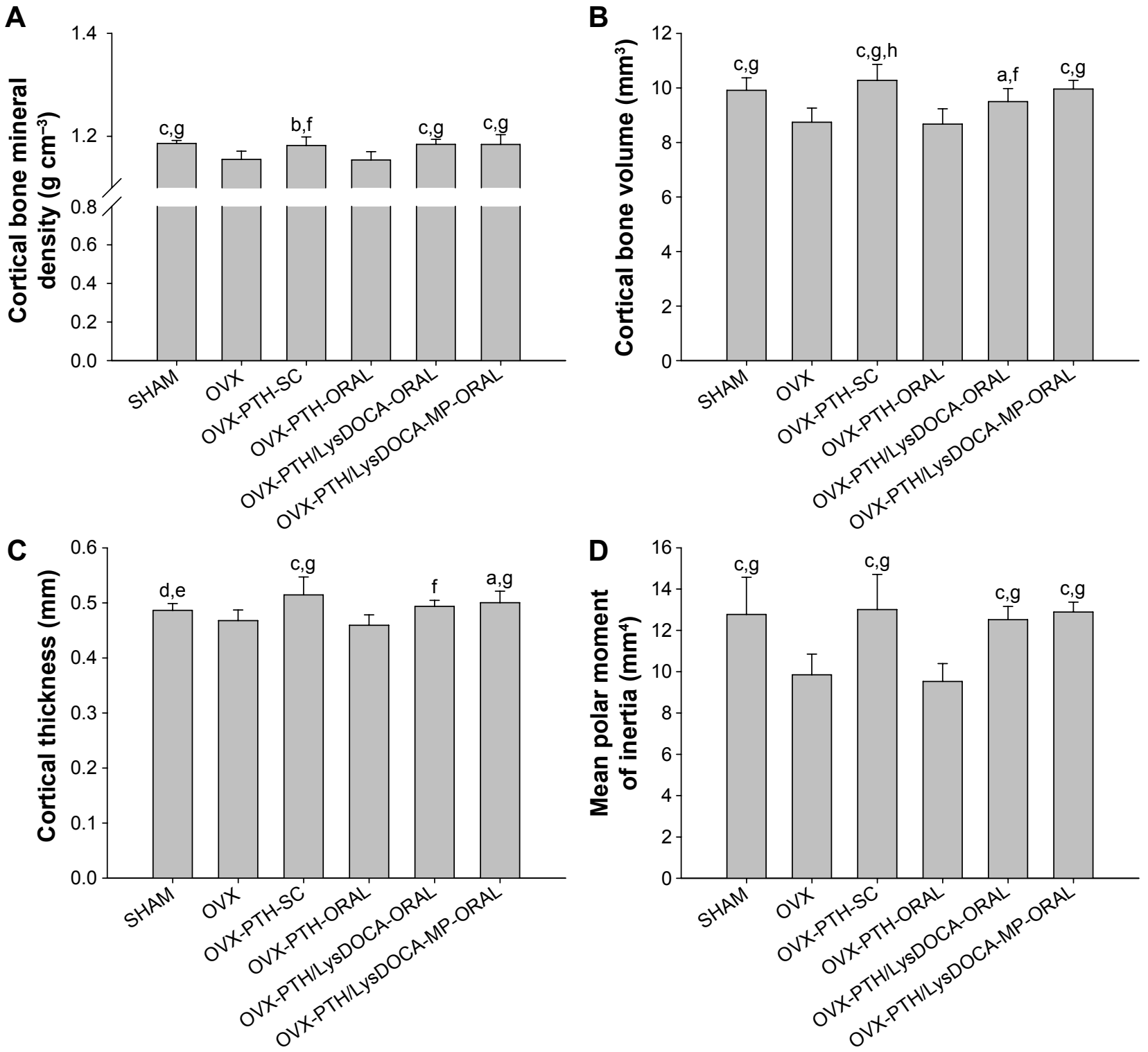

Figure 8 Micro-computed tomography ( $\mu-C T)$ analyses of the cortical bone of rat tibiae that were either sham-operated (SHAM) or ovariectomized (OVX) and treated with various modes.

Notes: The treatment modes were with once-daily subcutaneous injection of $10 \mu \mathrm{gg}^{-1} \mathrm{rhPTH}(\mathrm{I}-34)(\mathrm{OVX}-\mathrm{PTH}-\mathrm{SC})$ or once-daily oral administration of $50 \mu \mathrm{g} \mathrm{kg}^{-1}$ rhPTH (I-34) (OVX-PTH-ORAL), rhPTH (I-34)/Lys-DOCA complex as $50 \mu \mathrm{g} \mathrm{kg}{ }^{-1}$ rhPTH (I-34) (OVX-PTH/LysDOCA-ORAL), or enteric microparticles containing rhPTH (I-34)/ Lys-DOCA nanocomplex as $50 \mu \mathrm{g} \mathrm{kg}{ }^{-1}$ of rhPTH (I-34) (OVX-PTH/LysDOCA-MP-ORAL) for 12 weeks. Cortical bone mineral density (Ct.BMD) (A), cortical bone volume (Ct.BV) (B), cortical thickness (Ct.Th) (C), and mean polar moment of inertia (MMI [polar]) (D). Data are presented as mean \pm standard deviation ( $\mathrm{n}=10$ for each group). ${ }^{a} P<0.05$ compared with the OVX group; ${ }^{b} P<0.01$ compared with the OVX group; ${ }^{c} P<0.001$ compared with the OVX group; ${ }^{d} P<0.05$ compared with the OVX-PTH-SC group; e $P<0.05$ compared with the OVX-PTH-ORAL group; ${ }^{f} P<0.01$ compared with the OVX-PTH-ORAL group; $8 P<0.00$ I compared with the OVX-PTH-ORAL group; hP $<0.05$ compared with the OVX-PTH/LysDOCA-ORAL group (one-way ANOVA followed by Tukey's multiple-comparison test).

Abbreviations: PTH, parathyroid hormone; recombinant human PTH; LysDOCA, lysine-linked deoxycholic acid; ANOVA, analysis of variance. 
group, respectively. The OVX-PTH-SC group also exhibited $102 \%$ higher Ct.BMD, 118\% higher Ct.BV, 110\% higher Ct.Th, and $132 \%$ higher MMI (polar) than those of the OVX control group, and all parameters had levels similar to those of the OVX-PTH/LysDOCA-MP-ORAL group.

Representative 3D $\mu-\mathrm{CT}$ reconstructions and longitudinal cross-sections through the proximal tibia are shown in Figure 9. In contrast to the natural bone growth observed in the SHAM group, deterioration of the cancellous bone architecture was observed in the OVX control group. However, the OVX-PTH-SC and OVX-PTH/LysDOCA-MP-ORAL groups showed a denser trabecular microarchitecture of the proximal tibia than the OVX control or OVX-PTHORAL groups, suggesting greater anabolic effects from the subcutaneous injection of rhPTH (1-34) or oral administration of PTH/LysDOCA-loaded enteric microcapsules.

The same tendency was observed in histological sections from tibiae stained with H\&E (Figure 10). The SHAM group displayed dense, uniform trabeculae in contrast to the OVX control group, which showed disrupted trabecular connectivity. The OVX-PTH-SC and OVX-PTH/LysDOCAMP-ORAL groups showed increased structural integrity and denser trabecular microarchitecture than the OVX control and OVX-PTH-ORAL groups.

\section{Discussion}

For the long-term treatment of osteoporosis, oral teriparatide administration may improve patient compliance over oncedaily subcutaneous injection. ${ }^{29-31}$ This study is also important in terms of convenience when other bisphosphonate drugs are coadministered. However, administering therapeutic proteins or peptides orally can be challenging due to the characteristics of and limitations imposed by the GI tract. These include the potential for degradation by acid or proteolytic enzymes, poor intestinal membrane permeability, and first-pass metabolism during transfer to the liver. ${ }^{32-34}$ In the present study, we devised a functional delivery system that included an enteric coating to protect against enzymatic degradation and acidic conditions in the stomach in combination with an intestinal absorption enhancer utilizing the natural uptake processes (eg, bile transporters) to achieve optimized oral delivery of rhPTH (1-34).

Because proteins or peptides must be translocated across membranes to reach the appropriate subcellular location, we hypothesized the following mode of action for the PTH/LysDOCA nanocomplex: ${ }^{35}$ first, orally administered PTH/LysDOCA nanoparticles can be transported by the export or import system located in the intestinal membrane. The amphiphilic LysDOCA, comprising a hydrophobic DOCA moiety and positively charged lysine, interacts with negatively charged amino acids in rhPTH (1-34), enhancing the partition of rhPTH (1-34) into the lipophilic membrane. The formation of a PTH/LysDOCA (1:10) nanocomplex did not significantly alter the secondary structure of rhPTH (1-34) (Figure 1). The amphiphilic LysDOCA can form micelles around rhPTH (1-34) molecules and act as a surfactant, adjusting the hydrophilic-lipophilic balance. ${ }^{36}$ Thus, while the structure of the drug remained intact, its permeability and absorption through the intestinal membrane would be enhanced by changes in the mucosal barrier properties such
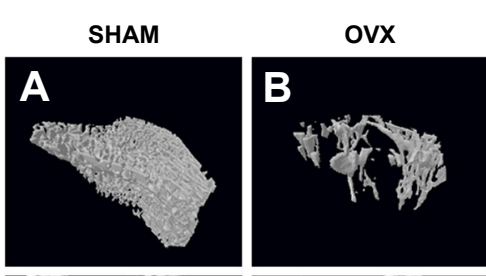

OVX-PTH-SC
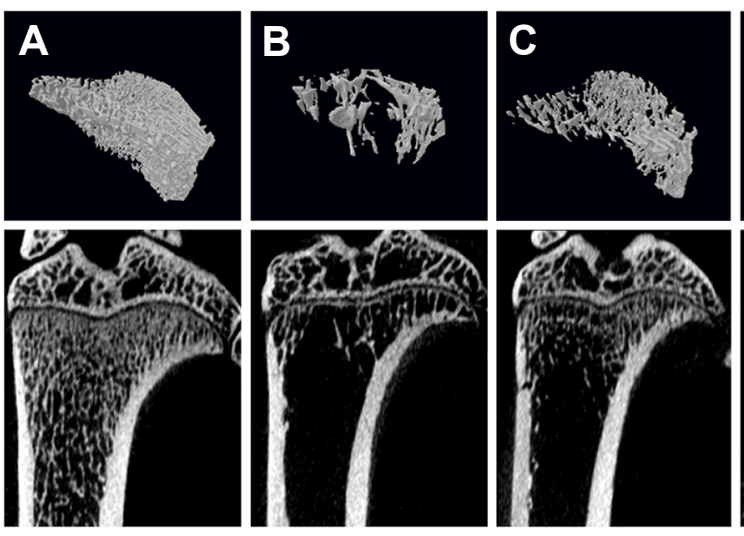

OVX-PTH-ORAL

OVX-PTH/LysDOCA- OVX-PTH/LysDOCA-
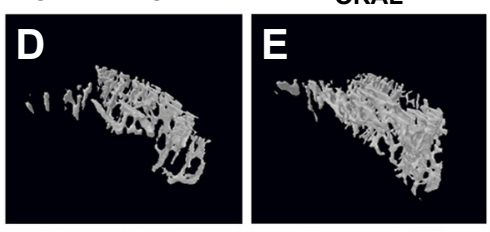
MP-ORAL
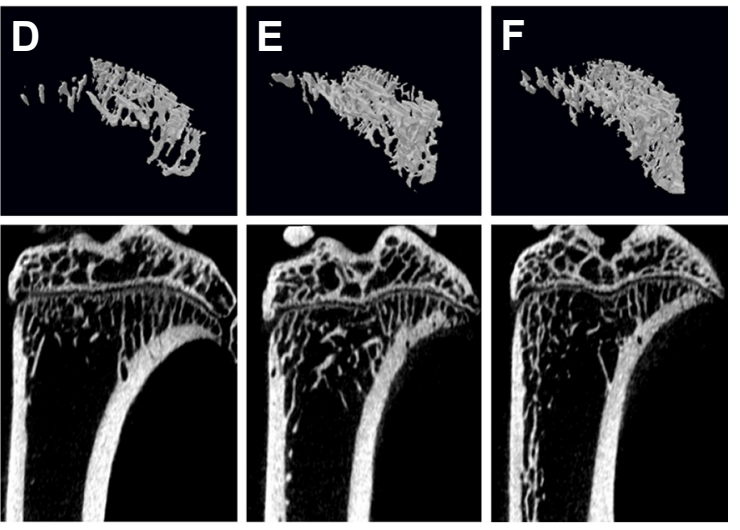

Figure 9 Representative 2D and 3D images of the distal rat tibiae that were either sham-operated (SHAM) or ovariectomized (OVX) and treated with various modes. Notes: Distal rat tibiae were either SHAM (A) or OVX (B). The treatment modes were once-daily subcutaneous injection of $10 \mu \mathrm{kg} \mathrm{g}^{-1}$ rhPTH (I-34) (OVX-PTH-SC) (C) or once-daily oral administration of $50 \mu \mathrm{gg}^{-1} \mathrm{rhPTH}$ (I-34) (OVX-PTH-ORAL) (D), rhPTH (I-34)/Lys-DOCA complex as $50 \mu \mathrm{gg}$ kg ${ }^{-1}$ of rhPTH (I-34) (OVX-PTH/ LysDOCA-ORAL) (E), or enteric-microparticles containing rhPTH (I-34)/Lys-DOCA nanocomplex as $50 \mu \mathrm{g} \mathrm{kg}{ }^{-1}$ of rhPTH (I-34) (OVX-PTH/LysDOCA-MP-ORAL) (F) for 12 weeks ( $\mathrm{n}=10$ for each group).

Abbreviations: PTH, parathyroid hormone; recombinant human PTH; LysDOCA, lysine-linked deoxycholic acid. 

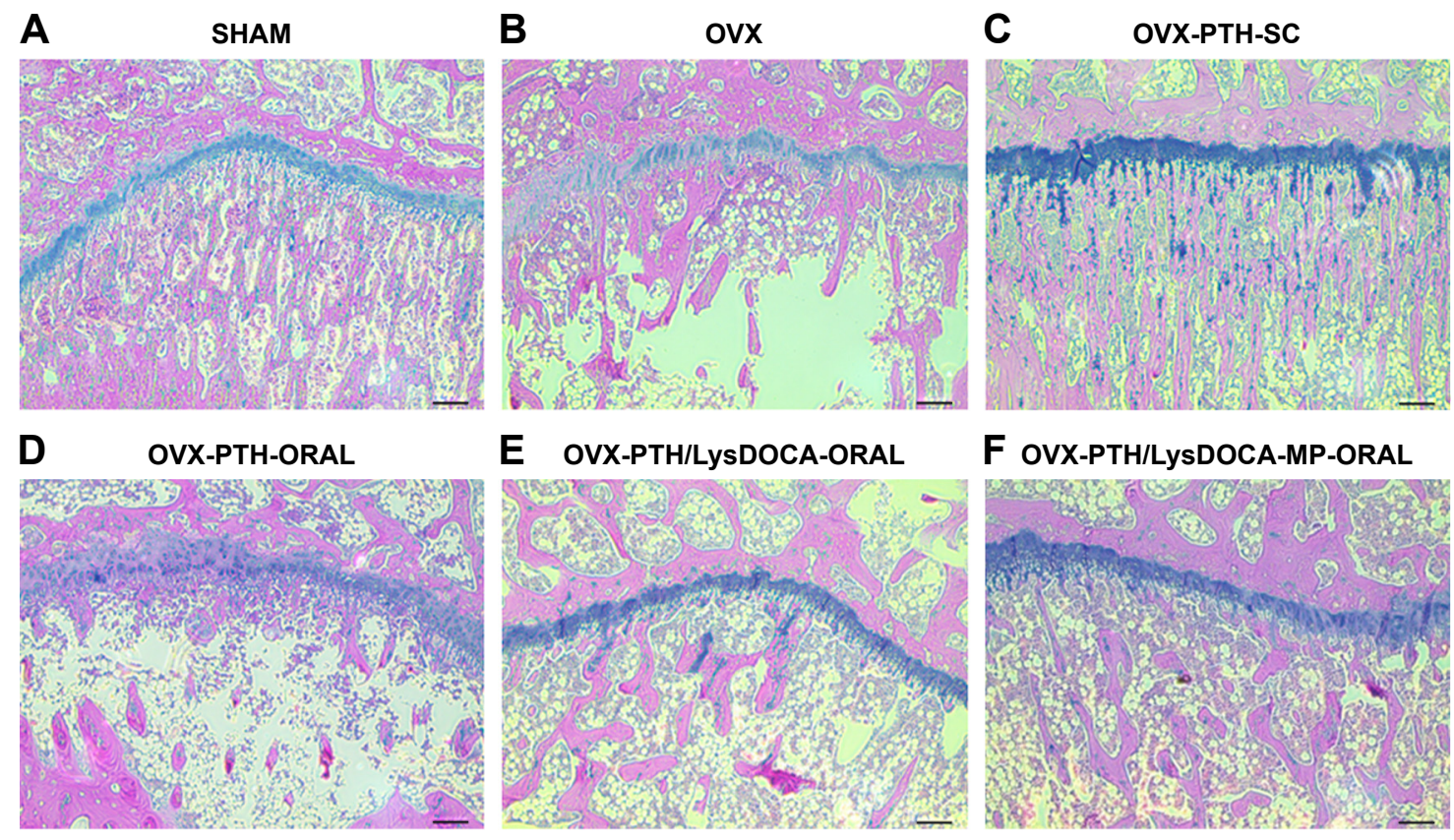

Figure 10 Representative longitudinal cross-sectional images of proximal rat tibiae stained with hematoxylin and eosin (H\&E) that were either sham-operated (SHAM) or ovariectomized $(\mathrm{OVX})$ and treated with various modes.

Notes: Cross-sectional images were either SHAM (A) or OVX (B). The treatment modes were once-daily subcutaneous injection of I0 $\mu \mathrm{g}$ kg-1 rhPTH (I-34) (OVX-PTHSC) (C) or once-daily oral administration of $50 \mu \mathrm{g} \mathrm{kg}{ }^{-1} \mathrm{rhPTH}$ (I-34) (OVX-PTH-ORAL) (D), rhPTH (I-34)/Lys-DOCA complex as $50 \mu \mathrm{g} \mathrm{kg}{ }^{-1}$ of rhPTH (I-34) (OVX-PTH/ LysDOCA-ORAL) (E), or enteric-microparticles containing rhPTH (I-34)/Lys-DOCA nanocomplex as $50 \mu \mathrm{g} \mathrm{kg}{ }^{-1}$ of rhPTH (I-34) (OVX-PTH/LysDOCA-MP-ORAL) (F) for 12 weeks ( $\mathrm{n}=10$ for each group). Scale bar $=200 \mu \mathrm{m}$.

Abbreviations: PTH, parathyroid hormone; recombinant human PTH; LysDOCA, lysine-linked deoxycholic acid.

as mucus rheology and membrane fluidity. This produces greater diffusion and absorption of rhPTH (1-34) as the molar ratio of LysDOCA is increased. ${ }^{37}$ The intestinal absorption of PTH/LysDOCA might also be enhanced via the interaction between LysDOCA and the apical sodium-dependent bile acid transporter. ${ }^{38}$ According to an absorption mechanism study of a physical drug/LysDOCA complex in the small intestine, the drug/LysDOCA complex was absorbed into intestinal segments, including the jejunum and ileum. The merged images visualized by confocal laser scanning microscopy from the jejunum and ileum suggested that the drug/ LysDOCA complex did not dissociate during the absorption in gut tissues. The drug/LysDOCA complex was not adsorbed onto the surface of epithelial cells but internalized into the intestinal villi. Previous studies have demonstrated that bile acid transporters expressed in the ileum interact with DOCA, affecting the concentration gradient across the intestinal membrane and the permeability of DOCA conjugates via a transcellular pathway. ${ }^{39,40}$ Because of these factors, the PTH/LysDOCA complex is absorbed by the intestine better than rhPTH (1-34) alone (Table 2 and Figure 4). However, a quantitative analysis method for LysDOCA concentrations in plasma has not been established yet. Further pharmacokinetic experiments will be performed in a future study.
Second, an $N$-terminal signal sequence on rhPTH (1-34) is recognized in the cell cytosol, mediating the transport of the peptide into the endoplasmic reticulum for delivery to PTH receptors on the target membrane..$^{41}$ NMR studies revealed the presence of two $\alpha$-helical domains, Glu4-Lys13 and Val21-Gln29, that are joined by a more flexible "hinge" region. ${ }^{42}$ The presence of two $\alpha$-helical segments in the secondary structure of PTH (1-34) is consistent with the CD spectra shown in Figure 1. The secondary structure of PTH (1-34) is retained after the ionic complex with LysDOCA is formed, which explains the comparable levels of cAMP production in rhPTH (1-34)-treated and PTH/LysDOCAtreated groups (Figure 3).

After cells expressing the type 1 PTH receptor are stimulated by PTH (1-34), second-messenger signaling systems including the adenylyl cyclase/PKA pathway and the phospholipase C/protein kinase $\mathrm{C}$ pathway may be activated. Because PTH (1-34) activates adenylyl cyclase and produces cAMP, the type $1 \mathrm{PTH}$ receptor may also activate other G-protein signaling cascades. ${ }^{43}$ Therefore, the increase in intracellular cAMP in the $0.01-1.0 \mu \mathrm{M}$ PTH (1-34) concentration range may be due to increased PTH bound to the membrane receptor and the activation of adenylate cyclase (Figure 3). As a low concentration of PTH (1-34) 
activates the cAMP/PKA pathway in osteoblasts, osteoblastic differentiation is accompanied by increases in steady-state mRNA levels of the PTH receptor and adenylate cyclase activity in response to PTH. However, PTH can stimulate osteoblasts and osteoclasts at the same time, the net effect of which depends on the kinetics of receptor activation. ${ }^{44} \mathrm{~A}$ steep decline in cAMP concentration at $100 \mu \mathrm{M}$ PTH (1-34) may be attributed to decreased receptor activity in the presence of elevated PTH levels, with changes in the levels of G protein or the catalytic subunit of adenylate cyclase.

Although the PTH/LysDOCA complex has anabolic activity, it could be degraded by gastric acid or proteolytic enzymes if administrated orally. ${ }^{45}$ Enzymes such as trypsin, chymotrypsin, and pepsin may degrade PTH (1-34) entirely within 5 minutes, with the assistance of membrane-bound aminopeptidases. To protect the PTH/LysDOCA complex against pepsin degradation and the acidic conditions of the stomach, we encapsulated the drug in an enteric coating containing $\mathrm{pH}$-sensitive polymers, using coaxial ultrasonic atomization. Ultrasonic atomization is a versatile technique used for the microencapsulation and delivery of bioactive substances, and particularly the generation of the core-shell structure of the microcapsules. ${ }^{46,47}$ One hypothesis explaining the core-shell structure formation is that the microdroplets delivered separately from the inner and outer inlets undergo mid-air collision and coalesce. This results in microdroplets from the inner flow becoming encapsulated in microdroplets from the outer nozzle, depending on the surface tension gradients and size ratios of the liquid particles. ${ }^{48,49}$ In this study, to encapsulate the PTH/LysDOCA complex in the core, the complex suspension and the pure Eudragit L100-55 solution were delivered to the inner core and outer layer, respectively. The microdroplets from the inner nozzle were successfully encapsulated by the polymer from the outer nozzle only when the inner flow rate was threefold less than that of the outer flow rate, similar to previous aqueous/polymer microencapsulation studies. ${ }^{50}$

The cumulative release pattern of the enteric microparticles indicates the stability of the formulation at gastric $\mathrm{pH}$ but a sustained release of PTH (1-34) at $\mathrm{pH} 6.8$ for up to 2 hours (Figure 6). Delays in the release of PTH (1-34) from the enteric microparticles may be due to differences in the thickness of the polymer membrane or to the size of microdroplets generated by the vibration energy of the ultrasonic atomizer. ${ }^{26}$

Intermittent exposure to rhPTH (1-34) by daily injection

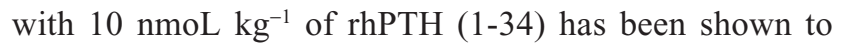
activate adenylyl cyclase and protein kinase $\mathrm{C}$ in osteoblastlike rat osteosarcoma cells, resulting in the growth of cortical and trabecular bone in OVX rats. ${ }^{51}$ The OVX rat model is often used in osteoporosis studies because the osteopenia and increased bone turnover induced by ovariectomy reflect characteristics of the condition. ${ }^{52}$ In patients with osteoporosis, BMD is reduced and microarchitectural deterioration of bone tissue occurs. Consequently, bones are more fragile and there is an increased risk of fractures. ${ }^{53}$ These changes can be assessed by bone biopsies and histological examination. To provide further insight into structural changes within the cancellous bone microarchitecture, nondestructive 3D $\mu$-CT imaging has also been utilized. ${ }^{54,55}$ Three-dimensional $\mu-\mathrm{CT}$ data demonstrated that the OVX-PTH-SC and OVX-PTH/ LysDOCA-MP-ORAL groups showed an anabolic response with greater trabecular thickness and connectivity as well as cortical bone parameters including cortical bone volume and thickness, and polar moment of inertia in the OVX rats than in the OVX control group (Figures 7-9). When PTH (1-34) is initially absorbed, the trabeculae become thicker, resulting in intratrabecular tunneling; this is in contrast to the response to antiresorptives, which do not have anabolic properties. ${ }^{56}$

In human clinical trials on postmenopausal women, 20-40 $\mu \mathrm{g} \mathrm{d}^{-1}$ of teriparatide administered by subcutaneous injection significantly lowered the number of fractures. ${ }^{57}$ The recommended dosing regimen for teriparatide was therefore assessed in our experimental setting. Intrajejunal administration of PTH/LysDOCA (1:10) nanocomplex (equivalent to $0.1 \mathrm{mg} \mathrm{kg}^{-1}$ of rhPTH [1-34]) increased $C_{\max }, \mathrm{AUC}_{\text {last}}$, and the relative bioavailability (subcutaneously) compared to intrajejunal administration of rhPTH (1-34) alone. The elapsed time until the last detectable plasma concentration of the drug, ie, $\sim 120$ minutes, also matched the intermittent exposure to teriparatide pattern that enhanced anabolic activity. Moreover, the OVX rats treated with oral PTH/ LysDOCA-loaded enteric microcapsules showed increases in BMD, BV/TV, Tb.Th, Tb.N, Ct.BV, Ct.Th, and MMI (polar) compared with the OVX control group. These increases were comparable with those observed in OVX rats treated with once-daily subcutaneous injections of rhPTH (1-34). The PTH/LysDOCA complex encapsulated in enteric microparticles increased bone-building activity compared with PTH/ LysDOCA complex alone because of its protection from the acid and enzymes of the GI tract.

This study is clinically more important than other related studies owing to the following advantages. In general, nonspecific permeation enhancers increase the intestinal membrane permeation of proteins and peptides by disrupting the membrane integrity, opening tight junction, or decreasing the mucus viscosity. However, permeation enhancers can be diluted by the large volume of GI fluids and thus cannot function effectively. Alternatively, macromolecules can be 
chemically conjugated with cell recognition moieties for specific interaction with transporters, such as di- and tripeptide transporters, glucose transporters, and vitamin B12 receptors, but this approach may cause the loss of biological activity. In contrast, our system based on the ionic complexation of macromolecular drugs with the enhancer can act using a minimum quantity of the enhancer, showing minimum toxicity while retaining the biological activity of the drug, because it enhances the drug permeability via specific binding to bile acid transporters in the intestinal membrane and/or an increase in concentration gradients across the membrane. Moreover, the enteric coating of the drug/LysDOCA complex can minimize degradation by gastric acid and proteolytic enzymes and synergistically enhance drug absorption.

Overall, enteric microencapsulated rhPTH (1-34)/ LysDOCA nanocomplexes exhibited enhanced oral absorption and equivalent therapeutic efficacies in comparison with teriparatide administered by injection, confirming our hypothesis.

\section{Conclusion}

Our study demonstrated that the rhPTH (1-34) nanocomplex with LysDOCA facilitates intestinal membrane permeability of rhPTH (1-34) without loss of the secondary structure, which is essential for bioactivity. Intrajejunally administered PTH/ LysDOCA nanocomplex in rats showed a 16.3-fold increase in $\mathrm{AUC}_{\text {last }}$ compared with rhPTH (1-34) alone. Oral administration of the PTH/LysDOCA complex, encapsulated in an enteric carrier by coaxial ultrasonic atomization, resulted in increases in BMD (159\%), BV/TV (175\%), and Tb.N (174\%) compared to an OVX control. Therefore, the oral delivery system using the PTH/LysDOCA nanocomplex results in improved osteogenesis and trabecular connectivity and could be a useful alternative in the treatment of osteoporosis.

\section{Acknowledgment}

This study was supported by research funds from Chosun University, 2013.

\section{Disclosure}

The authors report no conflicts of interest in this work.

\section{References}

1. Sherwood LM. Relative importance of parathyroid hormone and thyrocalcitonin in calcium homeostasis. $N$ Engl J Med. 1968;278(12): 663-670.

2. Poole KE, Reeve J. Parathyroid hormone - a bone anabolic and catabolic agent. Curr Opin Pharmacol. 2005;5(6):612-617.

3. Ishizuya $T$, Yokose $\mathrm{S}$, Hori M, et al. Parathyroid hormone exerts disparate effects on osteoblast differentiation depending on exposure time in rat osteoblastic cells. J Clin Invest. 1997;99(12):2961-2970.
4. Watson P, Lazowski D, Han V, Fraher L, Steer B, Hodsman A. Parathyroid hormone restores bone mass and enhances osteoblast insulinlike growth factor I gene expression in ovariectomized rats. Bone. 1995;16(3):357-365.

5. Jilka RL, Weinstein RS, Bellido T, Roberson P, Parfitt AM, Manolagas SC. Increased bone formation by prevention of osteoblast apoptosis with parathyroid hormone. J Clin Invest. 1999;104(4):439-446.

6. Ma YL, Cain RL, Halladay DL, et al. Catabolic effects of continuous human PTH (1-38) in vivo is associated with sustained stimulation of RANKL and inhibition of osteoprotegerin and gene-associated bone formation. Endocrinology. 2001;142(9):4047-4054.

7. Mannstadt M, Juppner H, Gardella TJ. Receptors for PTH and PTHrP: their biological importance and functional properties. Am J Physiol. 1999;277(5 pt 2):F665-F675.

8. Riek AE, Towler DA. The pharmacological management of osteoporosis. Mo Med. 2011;108(2):118-123.

9. Saag KG, Shane E, Boonen S, et al. Teriparatide or alendronate in glucocorticoid-induced osteoporosis. N Engl J Med. 2007;357(20): 2028-2039.

10. Teriparatide (forteo) for osteoporosis. Med Lett Drugs Ther. 2003; 45(1149):9-10.

11. Black DM, Delmas PD, Eastell R, et al. Once-yearly zoledronic acid for treatment of postmenopausal osteoporosis. N Engl J Med. 2007; 356(18):1809-1822.

12. Ettinger B, Black DM, Mitlak BH, et al. Reduction of vertebral fracture risk in postmenopausal women with osteoporosis treated with raloxifene: results from a 3-year randomized clinical trial. Multiple Outcomes of Raloxifene Evaluation (MORE) Investigators. JAMA. 1999; 282(7):637-645

13. Chesnut $\mathrm{CH} 3 \mathrm{rd}$, Silverman S, Andriano K, et al. A randomized trial of nasal spray salmon calcitonin in postmenopausal women with established osteoporosis: the prevent recurrence of osteoporotic fractures study. PROOF Study Group. Am J Med. 2000;109(4):267-276.

14. Hammerle SP, Mindeholm L, Launonen A, et al. The single dose pharmacokinetic profile of a novel oral human parathyroid hormone formulation in healthy postmenopausal women. Bone. 2012;50(4):965-973.

15. Lane NE, Silverman SL. Anabolic therapies. Curr Osteoporos Rep. 2010;8(1):23-27.

16. Matsumoto T, Shiraki M, Hagino H, Iinuma H, Nakamura T. Daily nasal spray of hPTH(1-34) for 3 months increases bone mass in osteoporotic subjects: a pilot study. Osteoporos Int. 2006;17(10):1532-1538.

17. Goldberg M, Gomez-Orellana I. Challenges for the oral delivery of macromolecules. Nat Rev Drug Discov. 2003;2(4):289-295.

18. Woodley JF. Enzymatic barriers for GI peptide and protein delivery. Crit Rev Ther Drug Carrier Syst. 1994;11(2-3):61-95.

19. Leone-Bay A, Sato M, Paton D, et al. Oral delivery of biologically active parathyroid hormone. Pharm Res. 2001;18(7):964-970.

20. Narayanan D, Anitha A, Jayakumar R, Nair SV, Chennazhi KP. Synthesis, characterization and preliminary in vitro evaluation of PTH 1-34 loaded chitosan nanoparticles for osteoporosis. J Biomed Nanotechnol. 2012;8(1):98-106.

21. Narayanan D, Anitha A, Jayakumar R, Chennazhi KP. In vitro and in vivo evaluation of osteoporosis therapeutic peptide PTH 1-34 loaded PEGylated chitosan nanoparticles. Mol Pharm. 2013;10(11): 4159-4167.

22. Jeon OC, Seo DH, Kim HS, Byun Y, Park JW. Oral delivery of zoledronic acid by non-covalent conjugation with lysine-deoxycholic acid: in vitro characterization and in vivo anti-osteoporotic efficacy in ovariectomized rats. Eur J Pharm Sci. 2016;82:1-10.

23. Park JW, Hwang SR, Jeon OC, Moon HT, Byun Y. Enhanced oral absorption of ibandronate via complex formation with bile acid derivative. J Pharm Sci. 2013;102(2):341-346.

24. Hubatsch I, Ragnarsson EG, Artursson P. Determination of drug permeability and prediction of drug absorption in Caco-2 monolayers. Nat Protoc. 2007;2(9):2111-2119.

25. Vogler GA. Anesthesia and analgesia. In: Suckow MA, Weisbroth SH, Franklin CL, editors. The Laboratory Rat. 2nd ed. Massachusetts: Elsevier Academic Press; 2006:627-664. 
26. Yeo Y, Park K. A new microencapsulation method using an ultrasonic atomizer based on interfacial solvent exchange. $J$ Control Release. 2004;100(3):379-388.

27. Perilli E, Le V, Ma B, Salmon P, Reynolds K, Fazzalari NL. Detecting early bone changes using in vivo micro-CT in ovariectomized, zoledronic acid-treated, and sham-operated rats. Osteoporos Int. 2010;21(8): 1371-1382.

28. Cohen FE, Strewler GJ, Bradley MS, et al. Analogues of parathyroid hormone modified at positions 3 and 6 . Effects on receptor binding and activation of adenylyl cyclase in kidney and bone. J Biol Chem. 1991; 266(3):1997-2004.

29. Gupta V, Hwang BH, Lee J, Anselmo AC, Doshi N, Mitragotri S. Mucoadhesive intestinal devices for oral delivery of salmon calcitonin. J Control Release. 2013;172(3):753-762.

30. Adami S, Passeri M, Ortolani S, et al. Effects of oral alendronate and intranasal salmon calcitonin on bone mass and biochemical markers of bone turnover in postmenopausal women with osteoporosis. Bone. 1995;17(4):383-390.

31. Dempster DW, Bolognese MA. Ibandronate: the evolution of a once-amonth oral therapy for postmenopausal osteoporosis. J Clin Densitom. 2006;9(1):58-65.

32. Park JW, Kim SJ, Kwag DS, et al. Multifunctional delivery systems for advanced oral uptake of peptide/protein drugs. Curr Pharm Des. 2015;21(22):3097-3110.

33. Amidon GL, Lee HJ. Absorption of peptide and peptidomimetic drugs. Annu Rev Pharmacol Toxicol. 1994;34:321-341.

34. Varamini P, Toth I. Recent advances in oral delivery of peptide hormones. Expert Opin Drug Deliv. 2016;13(4):507-522.

35. Schatz G, Dobberstein B. Common principles of protein translocation across membranes. Science. 1996;271(5255):1519-1526.

36. Hofmann AF, Mysels KJ. Bile salts as biological surfactants. Colloids Surf. 1987;30(1):145-173.

37. Aungst BJ. Intestinal permeation enhancers. J Pharm Sci. 2000;89(4): 429-442.

38. Mahmud F, Jeon OC, Al-Hilal TA, et al. Absorption mechanism of a physical complex of monomeric insulin and deoxycholyl-1-lysylmethylester in the small intestine. Mol Pharm. 2015;12(6):1911-1920.

39. Jeon OC, Hwang SR, Al-Hilal TA, et al. Oral delivery of ionic complex of ceftriaxone with bile acid derivative in non-human primates. Pharm Res. 2013;30(4):959-967.

40. Al-Hilal TA, Park J, Alam F, et al. Oligomeric bile acid-mediated oral delivery of low molecular weight heparin. J Control Release. 2014; 175:17-24.

41. Freeman MW, Wiren KM, Rapoport A, Lazar M, Potts JT Jr, Kronenberg HM. Consequences of amino-terminal deletions of preproparathyroid hormone signal sequence. Mol Endocrinol. 1987;1(9): 628-638.

42. Barden JA, Kemp BE. NMR solution structure of human parathyroid hormone(1-34). Biochemistry. 1993;32(28):7126-7132.

43. Abou-Samra AB, Juppner H, Force T, et al. Expression cloning of a common receptor for parathyroid hormone and parathyroid hormonerelated peptide from rat osteoblast-like cells: a single receptor stimulates intracellular accumulation of both cAMP and inositol trisphosphates and increases intracellular free calcium. Proc Natl Acad Sci US A. 1992;89(7):2732-2736.
44. Gesty-Palmer D, Luttrell LM. 'Biasing' the parathyroid hormone receptor: a novel anabolic approach to increasing bone mass? $\mathrm{Br}$ J Pharmacol. 2011;164(1):59-67.

45. Werle M, Samhaber A, Bernkop-Schnürch A. Degradation of teriparatide by gastro-intestinal proteolytic enzymes. J Drug Target. 2006; 14(3):109-115.

46. Park JH, Ye M, Yeo Y, Lee WK, Paul C, Park K. Reservoir-type microcapsules prepared by the solvent exchange method: effect of formulation parameters on microencapsulation of lysozyme. Mol Pharm. 2006;3(2):135-143.

47. Xie J, Ng WJ, Lee LY, Wang CH. Encapsulation of protein drugs in biodegradable microparticles by co-axial electrospray. $J$ Colloid Interface Sci. 2008;317(2):469-476.

48. Yeo Y, Basaran OA, Park K. A new process for making reservoir-type microcapsules using ink-jet technology and interfacial phase separation. J Control Release. 2003;93(2):161-173.

49. Dalmoro A, Barba AA, Lamberti G, d'Amore M. Intensifying the microencapsulation process: ultrasonic atomization as an innovative approach. Eur J Pharm Biopharm. 2012;80(3):471-477.

50. Wen Y, Gallego MR, Nielsen LF, Jorgensen L, Moller EH, Nielsen HM. Design and characterization of core-shell mPEG-PLGA composite microparticles for development of cell-scaffold constructs. Eur J Pharm Biopharm. 2013;85(1):87-98.

51. Rixon RH, Whitfield JF, Gagnon L, et al. Parathyroid hormone fragments may stimulate bone growth in ovariectomized rats by activating adenylyl cyclase. J Bone Miner Res. 1994;9(8):1179-1189.

52. Wronski TJ, Dann LM, Scott KS, Cintron M. Long-term effects of ovariectomy and aging on the rat skeleton. Calcif Tissue Int. 1989;45(6): 360-366.

53. Genant HK, Cooper C, Poor G, et al. Interim report and recommendations of the World Health Organization task-force for osteoporosis. Osteoporos Int. 1999;10(4):259-264.

54. Müller R, Hahn M, Vogel M, Delling G, Rüegsegger P. Morphometric analysis of noninvasively assessed bone biopsies: comparison of high-resolution computed tomography and histologic sections. Bone. 1996;18(3):215-220.

55. Hildebrand T, Laib A, Muller R, Dequeker J, Ruegsegger P. Direct three-dimensional morphometric analysis of human cancellous bone: microstructural data from spine, femur, iliac crest, and calcaneus. J Bone Miner Res. 1999;14(7):1167-1174.

56. Jerome CP, Burr DB, Van Bibber T, Hock JM, Brommage R. Treatment with human parathyroid hormone (1-34) for 18 months increases cancellous bone volume and improves trabecular architecture in ovariectomized cynomolgus monkeys (Macaca fascicularis). Bone. 2001;28(2):150-159.

57. Neer RM, Arnaud CD, Zanchetta JR, et al. Effect of parathyroid hormone (1-34) on fractures and bone mineral density in postmenopausal women with osteoporosis. N Engl J Med. 2001;344(19):1434-1441.
International Journal of Nanomedicine

\section{Publish your work in this journal}

The International Journal of Nanomedicine is an international, peerreviewed journal focusing on the application of nanotechnology in diagnostics, therapeutics, and drug delivery systems throughout the biomedical field. This journal is indexed on PubMed Central, MedLine, CAS, SciSearch ${ }^{\circledR}$, Current Contents ${ }^{\circledR} /$ Clinical Medicine,

\section{Dovepress}

Journal Citation Reports/Science Edition, EMBase, Scopus and the Elsevier Bibliographic databases. The manuscript management system is completely online and includes a very quick and fair peer-review system, which is all easy to use. Visit http://www.dovepress.com/ testimonials.php to read real quotes from published authors. 